\title{
LOS CENTROS ESPECIALES DE EMPLEO: CONFIGURACIÓN LEGAL E INCIDENCIA Y VALORACIÓN DE LAS ÚLTIMAS ACTUACIONES NORMATIVAS ${ }^{1}$
}

\author{
Luis Ángel Sánchez Pachón \\ Profesor Titular de Universidad \\ Universidad de Valladolid
}

\section{RESUMEN}

El reconocimiento legal de los Centros Especiales de Empleo (CEE) se produjo en la Ley 13/1982, de 7 de abril. La Ley 5/2011, de Economía Social, incluyó a los CEE dentro de las entidades de economía social. El Real Decreto Legislativo 1/2013 dio una nueva definición de los CEE. La Ley 9/2017, de 8 de noviembre, de contratos del sector público, produjo un cambio significativo en la tipificación de los CEE, repercutiendo en las reservas de contrataciones del sector público. En el trabajo repasamos esta evolución normativa, nos centramos en la caracterización actual de los CEE y en el cambio significativo producido en la Ley de 2017. El cambio no deja de ser polémico. En los pocos años de vigencia de la reforma surgen conflictos en su aplicación, discrepancias interpretativas, desajustes o colisiones con otras instituciones de nuestro sistema jurídico y no faltan, tampoco, voces críticas que cuestionan sus objetivos.

PALABRAS CLAVE: Economía social, centros especiales de empleo, contratación pública, contratos reservados.

CLAVES ECONLIT: B55, H57, J14, K12, L31.

Cómo citar este artículo/How to cite this article: SÁNCHEZ PACHÓN, L.A.: “Los Centros Especiales de Empleo: configuración legal e incidencia y valoración de las últimas actuaciones normativas", CIRIEC-España, Revista Jurídica de Economía Social y Cooperativa, n 36, 2020, pp. 55-91. DOI: 10.7203/CIRIEC-JUR.36.16989.

1. Este trabajo es resultado del proyecto de investigación "Economía Social, Autogestión y Empleo" (DER2016-78732-R) financiado por el Ministerio de Ciencia, Innovación y Universidades del Gobierno de España, por la Agencia Estatal de Investigación y por el Fondo Europeo de Desarrollo Regional. Investigador principal: Da Gemma Fajardo García. 
(pp. 55-91)

\section{SPECIAL EMPLOYMENT CENTERS: LEGAL CONFIGURATION AND INCIDENCE AND VALUATION OF THE LAST REGULATORY ACTIONS}

\section{EXPANDED ABSTRACT}

The legal recognition of the Special Employment Centers (CEE) occurred in Law 13/1982, of April 7, on the social integration of the disabled (LISMI), under the protection of art. 49 of the Spanish Constitution. The regulatory development took place through Royal Decree 2273/1985, of December 4, which approves the Regulation of the Special Employment Centers defined in article 42 of Law 13/1982, of April 7, on Integration Social of the Handicapped (sic) (BOE 12/09/1985).

In the following years we were able to attend some modification in the characterization of the CEE as well as some administrative measures to promote the employment of people with disabilities, such as the creation of labor enclaves, through Royal Decree 290/2004, of February 20, or the regulation of the support units for professional activity, in Royal Decree $469 / 2006$, framed within the adjustment services of the CEE.

The Act 5/2011, on the Social Economy, included the EWCs within social economy entities and Royal Legislative Decree 1/2013, which recasts and repeals, among others, Law 13/1982 (LISMI), gave a new definition of the CEE. However, it was in 2017 when the most significant change occurred. Change, apparently, that was being claimed by an important sector of Social Economy entities. However, in the two long years that we have been in force since its inception, conflicts arise in its application, interpretative discrepancies, imbalances or collisions with other institutions of our legal system, and there is no lack, either, of critical voices that question a certain sectarianism - some speak, even, of illegality- of the reform operated in 2017 that allows coverage of certain questionable actions, particularly in public procurement procedures.

The Act 9/2017 created the "Special Employment Centers of social initiative". These are those promoted and participated in more than $50 \%$ by one or several entities, public or private, that are not for profit or that have recognized their social character in their statutes. Such can be associations, foundations, public law corporations, cooperatives of social initiative or other social economy entities; but so will the centers of mercantile societies in which the majority of its capital stock is owned by any of those entities indicated, or by entities controlled by them. With this legal configuration, there are many doubts and also the risks of collusions for the creation of a social initiative EEC with the aim, for example, of having competitive advantages in public procurement. The reservations to the CEE of social initiative in some 
(pp. 55-91)

public contracts have already given rise to conflicts with other CEE. The European Directive $2014 / 24$ / EU is also invoked and the right to free competition is claimed.

In this situation, in which different interests converge, after reviewing the regulatory evolution in the characterization of the CEE, we seek to open the debate and reflection in the Social Economy sector and, in particular, in the CEE, to propose the corresponding regulatory adaptations and corrective measures that facilitate compliance with the institutional purposes entrusted to the CEE. All this will be done within a legal security framework that the system must always offer. In this discussion is interesting the Opinion of the European Economic and Social Committee "Towards an appropriate European legal framework for social economy enterprises" (own-initiative opinion), of June 19, 2019. It proposes to introduce into the EU legislation a legal framework adapted to a better recognition of the EES, in which a new concept of "limited benefits", would allow reconsidering the actions of companies that can obtain benefits, but not with in order to distribute them among their owners, but with a purpose of solidarity or general interest.

In our conclusions we highlight that the policies of social security, treatment, rehabilitation and integration of people with disabilities and specialized care, to guarantee their right to work, have a constitutional justification and recognition in the International Convention on the rights of people with disabilities (New York of December 13, 2006) ratified by Spain through an instrument of ratification published on April 21, 2008, and to which the European Union is linked, by means of a Council Decision of November 26, 2009.

The CEEs have been recognized in our legal system, for almost 40 years, they have been an instrument to avoid the job separation suffered by people with disabilities. The CEE are an opportunity for professional development and, therefore, for autonomy. In the current configuration of the CEEs, our legal system does not establish any limitation regarding the public or private nature of the entity, nor its legal form, nor its purpose (lucrative or not), or ownership, if applicable, of its share capital.

The main objective of the CEEs is to carry out a productive activity of goods or services and their purpose is to ensure gainful employment for people with disabilities, but, at the same time, they are a means of including the greatest number of these people in the ordinary employment regime. It is convenient to recover the CEE as a bridge or transit to employment in an ordinary company.

National and European regulations make it possible to justify the priority and reservations for EWCs (and insertion companies) in public sector contracting due to their different behavior compared to ordinary companies. What does not seem so justified is that this priority and 
reservations be limited to certain CEE, to CEE of social initiative, and even less that, for this, the Public Sector Contracts Law is used to modify the Law that configures CEEs, introducing an ad hoc category, which will not stop generating conflicts.

The CEE category of social initiative, added by the Public Sector Contracts Act of 2017, is still controversial and deserves to be revised. The Social Economy Law does not distinguish categories of special employment centers and calls for the promotion of all of them, so a specific type of CEE, which will have an advantageous treatment in public procurement, does not fit well into the system of Social Economy Law.

The Opinion of the European Economic and Social Committee, 'Towards an appropriate European legal framework for social economy enterprises", in the observations on Competition Law, it is said that this concept of limited benefits should apply to Competition Law and that, even when only the exercise of an economic activity in a market is used as a criterion to determine the scope of competition rules, it could be introduced adjustments in the application phase of the regulations, in order to take into account certain specificities of the Social Economy Entities.

Regarding public contraction, the Opinion states that the European Community considers that the access of Social Economy Entities to public contracts is a matter that requires attention and has highlighted the difficulty of some to participate in tenders and that these companies are excluded, a priori, from reserved contracts. However, there is a general exception for economic operators whose main objective is the social and professional integration of people with disabilities or disadvantaged. Furthermore, Directive 2014/24/EU also gives Member States the possibility of reserving health, social and cultural services contracts for companies with limited benefits that meet certain operating criteria.

This proposed new concept of "limited benefit" entities may perhaps be a way to better recognize Social Economy Entities and better care, and more respectful of competition law, in the sector's contract reserves public. This new concept, incorporated by public administrations in the contracting specifications, would facilitate, without distortion, we understand, the participation of social economy entities in tenders.

KEYWORDS: Social enterprises, public procurements, reserved procurements. 


\section{SUMARIO}

1. Planteamiento y objetivos. 2. Configuración legal de los centros especiales de empleo (CEE): la Ley 13/1982 de integración social de los minusválidos (LISMI) y su desarrollo normativo. 3. Los centros especiales de empleo en la Ley 5/2011 de Economía Social. 4. El Real Decreto Legislativo $1 / 2013$ de texto refundido de la ley general de las personas con discapacidad y de su inclusión laboral. 5. Incidencia de Ley de Contratos del Sector Público (Ley 9/2017, de 8 de noviembre) en los centros especiales de empleo y su problemática. 6 . Conclusiones y cuestiones pendientes. Bibliografía.

\section{Planteamiento y objetivos}

El reconocimiento legal de los Centros Especiales de Empleo (CEE) se produjo en la Ley 13/1982, de 7 de abril, de integración social de los minusválidos (LISMI) ${ }^{2}$, al amparo del artículo 49 de la $\mathrm{CE}^{3}$. Su desarrollo reglamentario tuvo lugar mediante el Real Decreto 2273/1985, de 4 de diciembre, por el que se aprueba el Reglamento de los Centros Especiales de Empleo definidos en el artículo 42 de la Ley 13/1982, de 7 de abril, de Integración Social del Minusválido (sic) (BOE 09/12/1985). En los ańos posteriores pudimos asistir a alguna modificación en la caracterización de los CEE así como a algunas medidas de carácter administrativo de fomento del empleo de las personas con discapacidad, como la creación de los enclaves laborales, mediante el Real Decreto 290/2004, de 20 de febrero, o la regulación de las unidades de

2. Mejor, ahora, Ley de integración social de las personas con discapacidad. Conviene advertir que la Disposición Adicional Octava de la Ley 39/2006, de 14 de diciembre, de Promoción de la Autonomía Personal y Atención a las personas en situación de dependencia dispone:

Disposición adicional octava. Terminología.

Las referencias que en los textos normativos se efectúan a "minusválidos" y a "personas con minusvalia", se entenderán realizadas a "personas con discapacidad".

A partir de la entrada en vigor de la presente Ley, las disposiciones normativas elaboradas por las Administraciones Públicas utilizarán los términos "persona con discapacidad" o "personas con discapacidad" para denominarlas.

3. Artículo 49 Constitución Espańola: Los poderes públicos realizarán una política de previsión, tratamiento, rehabilitación e integración de los disminuidos físicos, sensoriales y psíquicos a los que prestarán la atención especializada que requieran y los ampararán especialmente para el disfrute de los derechos que este Título otorga a todos los ciudadanos. En dicho Titulo se encuentra, entre otros, el derecho al trabajo (art. 35 C.E). Derecho al trabajo que, por lo demás, tiene también su reconocimiento en el Artículo 23 de la Declaración Universal de Derechos Humanos, de la Asamblea General de la Organización de las Naciones Unidas (Resolución 217 A (III) de 10 de diciembre de 1948). 
apoyo a la actividad profesional, en el Real Decreto 469/2006, enmarcadas dentro de los servicios de ajuste de los CEE.

La Ley 5/2011, de Economía Social, incluyó a los CEE dentro de las entidades de economía social y el Real Decreto Legislativo 1/2013, que refunde y deroga, entre otras, la Ley 13/1982 (LISMI), dio una nueva definición de los CEE. Pero fue en el año 2017 cuando se produjo el cambio más significativo. Cambio que, al parecer, venía reclamándose por un importante sector de las entidades de Economía Social. Sin embargo, en los dos ańos largos que llevamos desde su vigencia surgen conflictos en su aplicación, discrepancias interpretativas, desajustes o colisiones con otras instituciones de nuestro sistema jurídico y no faltan, tampoco, voces críticas que cuestionan cierto sectarismo -algunas han hablado, incluso, de ilegalidad- de la reforma operada en 2017 que permite dar cobertura a ciertas actuaciones cuestionables, particularmente, en los procedimientos de contratación pública.

La Ley 9/2017 creó los "Centros Especiales de Empleo de iniciativa social”. Éstos son los promovidos y participados en más de un $50 \%$ por una o varias entidades, públicas o privadas, que no tengan ánimo de lucro o que tengan reconocido su carácter social en sus estatutos. Así pueden serlo las asociaciones, fundaciones, corporaciones de derecho público, cooperativas de iniciativa social u otras entidades de la economía social. Aunque también lo serán los centros de sociedades mercantiles si en ellas la mayoría de su capital social es propiedad de alguna de esas entidades señaladas, o de entidades controladas por ellas.

Con esta configuración jurídica las dudas son muchas y también los riesgos de confabulaciones para la creación de CEE de iniciativa social con el fin, por ejemplo, de tener ventajas competitivas en la contratación pública. Por otra parte, las reservas a los CEE de iniciativa social en algunas contrataciones públicas ya han dado lugar a conflictos con otros CEE. Se invoca también la Directiva Europea 2014/24/UE y se reivindica el Derecho a la libre competencia.

En esta situación, en la que confluyen distintos intereses, después de repasar la evolución normativa en la caracterización de los CEE, buscamos abrir el debate y la reflexión en el sector de la Economía Social y, en particular, en el de los CEE, para proponer las correspondientes adaptaciones normativas y medidas correctoras que faciliten el cumplimiento de los fines institucionales que se encomiendan a los CEE. Todo ello dentro de un marco de seguridad jurídica que el sistema siempre ha de ofrecer. En este debate resulta de interés el Dictamen del Comité Económico y Social Europeo de 19 de junio de 2019: Hacia un marco jurídico europeo adaptado para las empresas de economía social (EES). En él se propone introducir en la legislación de la UE un marco jurídico adaptado a un mejor reconocimiento de las EES, en el que un nuevo concepto de «beneficios limitados», permitiría reconsiderar las actuaciones de 
(pp. 55-91)

las empresas que pueden obtener beneficios, pero no con el fin de distribuirlos entre sus propietarios, sino con una finalidad de tipo solidario o de interés general.

\section{Configuración legal de los centros especiales de empleo (CEE): la Ley 13/1982 de integración social de los minusválidos (LISMI) y su desarrollo normativo}

La Ley 13/1982 de integración social de los minusválidos (Ley de integración social de las personas con discapacidad) se ha venido reconociendo como la ley impulsora en la ordenación de un sistema de apoyos, prestaciones y medidas en un amplio abanico de áreas (social, laboral, educación, etc.) y como garantista, en igualdad de condiciones al resto de la población, de los derechos de las personas con discapacidad $^{4}$. A partir de esta Ley, como se ha dicho, las políticas desarrolladas cambian el rol de la persona con discapacidad y de sujeto pasivo, a que hay que atender, se pasa a sujeto activo, contribuyendo a un cambio en la percepción social de las personas con discapacidad y de la propia sociedad. La década de los 80 supuso para el Estado español pasar de un modelo individual de la discapacidad a un modelo social, esto es, "ya no se trataba de adaptar la persona con discapacidad al entorno social, sino de adaptar el entorno social a la persona con discapacidad. Por lo tanto, es la sociedad o el propio operador jurídico, quien tiene la responsabilidad de suprimir las barreras"s.

No procede ahora entrar en el análisis minucioso del articulado de la esa Ley; resumidamente cabe señalar que la LISMI establece las bases de los CEE en los artículos 37 y 41 . El 37 establece como fin primordial de las políticas de empleo la integración en el mercado ordinario o, en su defecto, al empleo protegido. El 41 establece que

4. Vid. MORATALLA SANTAMARÍA, P.: "Centros especiales de empleo", CIRIEC-España, Revista Jurídica de Economía Social y Cooperativa, núm. 29, 2016, p. 4, quien habla del "avance relevante en la época” que supuso la LISMI.

5. Vid. MONTALBÁN MOYA, R.: "Acta del IV Encuentro Nacional de investigadores y profesionales sobre economía social, autogestión y empleo (Valencia 14-25 de junio 2018)”. En La promoción del emprendimiento y la inserción social desde la economía social, (Coord. GEMMA FAJARDO, G.), Centro Internacional de Investigación e Información sobre la Economía Pública, Social y Cooperativa, CIRIEC-España, Valencia, pp. 19-21. Los CEE han sido considerados por la mayoría de los estudios como una herramienta eficaz de generación de empleo para las personas con discapacidad. Tales organizaciones proporcionan alternativas de empleo más seguras que el empleo ordinario. No obstante, durante los últimos años han surgido corrientes críticas que señalan que este tipo de centros contribuye a la segregación de las personas con discapacidad y que, en lugar de constituirse como puente, son un punto de destino para el colectivo de personas con discapacidad. Vid, MENDOZA JIMÉNEZ, J., ROMÁN CERVANTES, C. \& HERNÁNDEZ LÓPEZ, M.: "La economía social y la contratación pública: la herramienta de los contratos reservados", CIRIEC-España, Revista de Economía Pública Social y Cooperativa, núm. 97, 2019, pp. 225-226, y referencias ahí indicadas. 
serán objeto del empleo protegido quienes no puedan, provisional o definitivamente, ejercer una actividad laboral en las condiciones habituales. El artículo 10 establece la existencia de equipos multiprofesionales para atender a las personas con discapacidad (PCD) y garantizar su integración sociocomunitaria. El artículo 46 especifica, entre otras funciones, someter a revisiones periódicas a las PCD en CEE para impulsar su promoción. Otras funciones, según el artículo 10 serían la valoración de la discapacidad y el diagnóstico y orientación. El artículo 43 de la LISMI establece la necesidad de compensaciones económicas para los CEE y el 45 que pueden ser creados tanto por organismos públicos o privados como empresas ${ }^{6}$.

Sí es necesario que nos fijemos en la configuración que ahí se establecía para los CEE. En su artículo 41 la LISMI disponía:

\section{Artículo cuarenta y uno.}

Uno. Los minusválidos que por razón de la naturaleza o de las consecuencias de sus minusvalias no puedan, provisional o definitivamente, ejercer una actividad laboral en las condiciones habituales, deberán ser empleados en centros Especiales de Empleo, cuando su capacidad de trabajo sea igual o superior a un porcentaje de la capacidad habitual que se fijará por la correspondiente norma reguladora de la relación laboral de carácter especial de los trabajadores minusválidos que presten sus servicios en Centros Especiales de Empleo.

Dos. Cuando la capacidad residual de los minusválidos no alcanzara el porcentaje establecido en el apartado anterior, accederán en su caso a los Centros Ocupacionales previstos en el titulo VIII de esta Ley.

Tres. Los equipos multiprofesionales de valoración previstos en el artículo diez determinarán, en cada caso, mediante resolución motivada, las posibilidades de integración real y la capacidad de trabajo de los minusválidos a que se refieren los apartados anteriores.

Y el artículo 42 caracterizaba los Centros Especiales de Empleo:

\section{Artículo cuarenta y dos.}

Uno. Los Centros Especiales de Empleo son aquellos cuyo objetivo principal sea el de realizar un trabajo productivo, participando regularmente en las operaciones del mercado, y teniendo como finalidad el asegurar un empleo remunerado y la 
Los Centros Especiales de Empleo: configuración legal e incidencia y valoración de...

(pp. 55-91)

prestación de servicios de ajuste personal y social que requieran sus trabajadores minusválidos; a la vez que sea un medio de integración del mayor número de minusválidos al régimen de trabajo normal.

Dos. La totalidad de la plantilla de los Centros Especiales de Empleo estará constituida por trabajadores minusválidos, sin perjuicio de las plazas en plantilla del personal no minusválido imprescindible para el desarrollo de la actividad.

Se diferenciaban así los Centros Especiales de Empleo (CEE) de los Centros Ocupacionales. Estos, conforme a su artículo 53, habrían de tener como finalidad asegurar los servicios de terapia ocupacional y de ajuste personal y social a los minusválidos cuya acusada minusvalía temporal o permanente les impida su integración en una Empresa o en un Centro Especial de Empleo. Y encomendaba a las Administraciones Públicas dictar las normas específicas para autorizar su creación y funcionamiento que sería competencia tanto de dichas Administraciones Públicas como de las Instituciones o personas jurídicas privadas sin ánimo de lucro, atendiendo estas últimas, en todo caso, a las normas que para su creación y funcionamiento se dicten..."

El Real Decreto 2273/1985, de 4 de diciembre (BOE 09/12/1985), aprobó el Reglamento de los Centros Especiales de Empleo definidos en el artículo 42 de la LISMI $^{7}$. Texto que se mantiene vigente aunque con las correspondientes modificaciones, unas veces expresas y otras tácitas como consecuencia de la modificación legal posterior, como ocurrirá, por ejemplo, con el mismo párrafo segundo de su artículo $1^{8}$.

Este Reglamento sigue reconociendo que los CEE pueden no solo ser públicos o privados, sino con ánimo de lucro o sin él ${ }^{9}$. No se establecen así diferencias entre

7. Algunos de los aspectos fundamentales de estructura y organización que se recogen en el Real Decreto pueden verse en MORATALLA SANTAMARÍA, P.: cit., pg. 11 y ss. Vid., también, JORDÁN DE URRÍES VEGA, F. DE B. \& VERDUGO ALONSO, M.A.: cit., p. 5; CAVAS MARTÍNEZ, F. \& GRIMALDOS GARCÍA, M.: "Los centros especiales de empleo". En La empresa social y su organización jurídica (Coord. ANDREU MARTÍ, Ma.M.), Marcial Pons, 2014, pp. 179 y 184-187.

8. En su párrafo segundo dispone: La totalidad de la plantilla de los Centros Especiales de Empleo estará constituida por trabajadores minusválidos, sin perjuicio de las plazas en plantilla del personal no minusválido, imprescindible para el desarrollo de su actividad. Debiendo tenerse en cuenta que, como veremos, hoy por hoy, el Real Decreto Legislativo 1/2013, de 29 de noviembre, por el que se aprueba el Texto Refundido de la Ley General de derechos de las personas con discapacidad y de su inclusión social, en su art. 43.2 establece que "la plantilla de los centros especiales de empleo estará constituida por el mayor número de personas trabajadoras con discapacidad que permita la naturaleza del proceso productivo y, en todo caso, por el 70 por 100 de aquélla. A estos efectos no se contemplará el personal sin discapacidad dedicado a la prestación de servicios de ajuste personal y social."

9. Art. 5 del Real Decreto 2273/1985:

a) Según su titularidad, los Centros Especiales de Empleo podrán tener carácter público o privado. 
los CEE; únicamente, se tendrá en cuenta la posibilidad de percibir compensaciones económicas en el caso de que los no lucrativos tengan necesidad de financiación para situaciones de pérdidas ${ }^{10}$.

Establece también el Reglamento que la creación de Centros Especiales de Empleo exigirá su calificación e inscripción en el Registro de Centros que la Administración Central, o, en su caso, las Administraciones Autonómicas, crearán dentro de su ámbito de competencias (art. 7). Para su creación han de cumplir los requisitos que señala ese mismo precepto y, en lo que concierne a los de ámbito estatal ${ }^{11}$, cumplimentar las exigencias de la Orden de 16 de marzo de $1983^{12}$.

Aquel apartado 2 del art. 42 de la Ley 13/1982, se modificó por la disposición adicional 39.2 de la Ley 66/1997, de 30 de diciembre, de Medidas Fiscales, Administrativas y del Orden Social (Ley de Acompañamiento a los Presupuestos Generales del Estado) entrando en vigor el 1 de enero de 1998:

\section{Artículo cuarenta y dos.}

Dos. La plantilla de los Centros Especiales de Empleo estará constituida por el mayor número de trabajadores minusválidos que permita la naturaleza del proceso productivo y, en todo caso, por el 70 por 100 de aquélla. A estos efectos no se contemplará el personal no minusválido dedicado a la prestación de servicios de ajuste personal y social.

Se entenderán por servicios de ajuste personal y social los de rehabilitación, terapéuticos, de integración social, culturales y deportivos que procuren al trabajador minusválido del Centro Especial de Empleo una mayor rehabilitación personal y una mejor adaptación de su relación social.

El Real Decreto 290/2004, de 20 de febrero (BOE, 21 de febrero 2004), regula los enclaves laborales, como una medida de fomento del empleo de las personas con discapacidad. Entre sus objetivos, se venía a decir, estaba el favorecer el tránsito desde el empleo en los CEE al empleo en empresas del mercado ordinario de trabajo de

b) Atendiendo a la aplicación de sus posibles beneficios, los Centros podrán carecer o no de ánimo de lucro, según que aquellos repercutan en su totalidad en la propia institución o se aproveche parte de ellos en otra finalidad distinta que haya de cubrir la Entidad titular del mismo.

10. Vid. GARCÍA SABATER, A.B.: "Centros especiales de empleo de iniciativa social. Avances legislativos y ajustes necesarios”, CIRIEC-España, Revista Jurídica de Economía Social y Cooperativa, no 35, 2019, p. 6.

11. Vid. JORDÁN DE URRÍES VEGA, F. DE B. \& VERDUGO ALONSO, M.A.: cit., pp. 10 y 91-91, sobre normas de transferencias y desarrollos normativos de los CEE en las diferentes comunidades autónomas. 
(pp. 55-91)

personas con discapacidad ${ }^{13}$. Se entiende por enclave laboral el contrato entre una empresa del mercado ordinario de trabajo, llamada empresa colaboradora, y un Centro Especial de Empleo para la realización de obras o servicios que guarden relación directa con la actividad normal de aquélla y para cuya realización un grupo de trabajadores con discapacidad del Centro Especial de Empleo se desplaza temporalmente al centro de trabajo de la empresa colaboradora (artículo 1.2).

El mecanismo, como se ha dicho, habría de resultar sencillo: se trataba de que trabajadores con discapacidad contratados por un CEE efectuaran obras o servicios para y en una empresa ordinaria, buscando la normalización del empleo de personas con discapacidad en las empresas ordinarias y actuando como pasarela del empleo protegido al empleo ordinario ${ }^{14}$.

Con todo, no parece, al menos hasta el momento, que estos enclaves laborales hayan tenido los mejores resultados. Ya en el Informe de 2008 Trayectorias laborales de las personas con discapacidad y centros especiales de empleo, análisis empírico con la $M C V L^{15}$, se vino a decir que el "análisis econométrico permite concluir que este tipo de centros no contribuyen a la inserción de las personas con discapacidad en el

\section{Artículo 2. Objetivos de los enclaves laborales.}

Son objetivos de los enclaves laborales los siguientes:

a) Favorecer el tránsito desde el empleo en los centros especiales de empleo al empleo en empresas del mercado ordinario de trabajo de las personas con discapacidad y, en particular, de aquellas que por sus caracteristicas individuales presentan especiales dificultades para el acceso al mercado ordinario de trabajo de acuerdo con lo establecido en el artículo 6.2.

b) Permitir a los trabajadores con discapacidad de un centro especial de empleo desarrollar su actividad laboral en una empresa del mercado ordinario de trabajo completando, en todo caso, su experiencia profesional mediante el desarrollo de los trabajos, tareas y funciones que se realicen en tal empresa, facilitando de esta manera sus posibilidades de acceso al mercado ordinario de trabajo.

c) Conseguir que la empresa del mercado ordinario de trabajo en la que se realiza el enclave laboral tenga un mejor conocimiento de las capacidades y aptitudes reales de los trabajadores con discapacidad, como paso previo a su eventual incorporación a la plantilla de la empresa.

d) Posibilitar el crecimiento de la actividad desarrollada por los centros especiales de empleo y, por tanto, la contratación por éstos de nuevos trabajadores con discapacidad, favoreciendo la creación de empleo estable para personas con discapacidad.

e) Facilitar a las empresas el cumplimiento de la obligación de la cuota de reserva legal del dos por ciento de trabajadores con discapacidad establecida en el artículo 38.1 de la Ley 13/1982, de 7 de abril, de integración social de los minusválidos, transitoriamente, como medida alternativa en los términos previstos en este real decreto y, definitivamente, mediante la contratación directa de los trabajadores con discapacidad del enclave por la empresa colaboradora u otra empresa del mercado ordinario de trabajo.

14. Vid. CAVAS MARTÍNEZ, F. \& GRIMALDOS GARCÍA, M.: cit., p. 177 y referencias citadas en su nota núm. 15.

15. CUETO IGLESIAS, B. et al.: Trayectorias laborales de las personas con discapacidad y centros especiales de empleo, análisis empírico con la MCVL, http://www.seg-social.es/wps/wcm/connect/wss/be250769-afa44d91-ba1d-e4277cda9804/F10_07N.pdf?MOD=AJPERES\&amp;CVID= . 2008. 
mercado de trabajo ordinario, es decir, no son una forma de tránsito a la empresa ordinaria sino un destino en sí mismos" ${ }^{16}$.

El Real Decreto 469/2006, de 21 de abril (BOE del 24), reguló por primera vez las unidades de apoyo a la actividad profesional ${ }^{17}$. Se trata de equipos multiprofesionales enmarcados dentro de los servicios de ajuste personal y social de los CEE que, mediante el desarrollo de distintas funciones y cometidos, permiten ayudar a superar las barreras ${ }^{18}$. En la configuración que después se va a hacer de los CEE en el Real Decreto Legislativo 1/2013, las unidades de apoyo aparecen como el medio para la prestación de los servicios de ajuste de personal y social que requieran las personas con discapacidad. Entendiéndose por servicios de ajuste de personal y social "los que permitan ayudar a superar las barreras, obstáculos o dificultades que las personas trabajadoras con discapacidad de los centros especiales de empleo tengan en el proceso de incorporación a un puesto de trabajo, así como en la permanencia y progresión en el mismo", comprendiéndose también "aquellos dirigidos a la inclusión social, cultural y deportiva”.

\section{Los centros especiales de empleo en la Ley 5/2011 de Economía Social}

El artículo 2 de la Ley 5/2011 de la Ley de Economía Social, conceptúa a la economía social como: conjunto de las actividades económicas y empresariales, que en el ámbito privado llevan a cabo aquellas entidades que, de conformidad con los principios recogidos en el artículo 4, persiguen bien el interés colectivo de sus integrantes, bien el interés general económico o social, o ambos. En el artículo 4 la Ley enuncia esos principios orientadores que han de constituir la base de actuación de las entidades de la economía social ${ }^{19}$.

16. Vid., más referencias en CAVAS MARTÍNEZ, F. \& GRIMALDOS GARCÍA, M.: cit., p. 177 y 178 y su notas núm. 16 y 18. JORDÁN DE URRÍES VEGA, F. DE B. \& VERDUGO ALONSO, M.A.: cit., p. 20.

17. La norma fue derogada por la disposición derogatoria única.1.e) del Real Decreto-ley 3/2011, de 18 de febrero. No obstante, permanecería en vigor hasta que se aprobase la Estrategia Española de Empleo y el Plan Anual de Política de Empleo para el ejercicio 2012, según establece la disposición transitoria 3 del citado Real Decreto-ley. Por las disposiciones derogatoria única.1.h) y final 12.1.e) del Real Decreto-ley 3/2012, de 10 de febrero y de la Ley 3/2012, de 6 de julio, se deja sin efecto la derogación y se le da el carácter de medida estatal en el marco de la Estrategia Española de Empleo 2012-2014.

18. Sobre las mismas, vid., CAVAS MARTÍNEZ, F. \& GRIMALDOS GARCÍA, M.: cit., pp. 181-182.

19. a) Primacía de las personas y del fin social sobre el capital, que se concreta en gestión autónoma y transparente, democrática y participativa, que lleva a priorizar la toma de decisiones más en función de las personas y sus apor- 
El artículo 5 de la Ley de Economía Social, en su número uno, siempre ha incluido entre las entidades de economía social a los centros especiales de empleo ${ }^{20}$, sin ulteriores calificativos o caracterizaciones. Conforme a sus tres apartados originales, el artículo 5 nos ha permitido delimitar las entidades que forman parte de la economía social con arreglo a un triple criterio ${ }^{21}$ :

taciones de trabajo y servicios prestados a la entidad o en función del fin social, que en relación a sus aportaciones al capital social.

b) Aplicación de los resultados obtenidos de la actividad económica principalmente en función del trabajo aportado y servicio o actividad realizada por las socias y socios o por sus miembros y, en su caso, al fin social objeto de la entidad.

c) Promoción de la solidaridad interna y con la sociedad que favorezca el compromiso con el desarrollo local, la igualdad de oportunidades entre hombres y mujeres, la cohesión social, la inserción de personas en riesgo de exclusión social, la generación de empleo estable y de calidad, la conciliación de la vida personal, familiar y laboral y la sostenibilidad.

d) Independencia respecto a los poderes públicos.

Su contenido ha sido objeto de detenido análisis en nuestra doctrina, vid. Referencias en SÁNCHEZ PACHÓN, L.A. \& PÉREZ CHINARRO, E.: "Las entidades de economía social como protagonistas de un nuevo modelo de emprendimiento y medidas legales de apoyo al emprendimiento", CIRIEC-España, Revista de economía pública, social y cooperativa, no. 84, 2015, p. 44. Más recientemente, FAJARDO GARCÍA, G.: "La identificación de las empresas de economía social en Espańa. Problemática jurídica", REVESCO, Revista de estudios Cooperativos, 128, 2018, pp. 104 y ss.

20. Los tres números de la redacción original el artículo 5 disponían:

Artículo 5. Entidades de la economía social.

1. Forman parte de la economía social las cooperativas, las mutualidades, las fundaciones y las asociaciones que lleven a cabo actividad económica, las sociedades laborales, las empresas de inserción, los centros especiales de empleo, las cofradias de pescadores, las sociedades agrarias de transformación y las entidades singulares creadas por normas especificas que se rijan por los principios establecidos en el articulo anterior.

2. Asimismo, podrán formar parte de la economía social aquellas entidades que realicen actividad económica y empresarial, cuyas reglas de funcionamiento respondan a los principios enumerados en el artículo anterior, y que sean incluidas en el catálogo de entidades establecido en el artículo 6 de esta Ley.

3. En todo caso, las entidades de la economía social se regularán por sus normas sustantivas especificas.

21. Vid. SÁNCHEZ PACHÓN, L.A. \& PÉREZ CHINARRO, E.: cit., p. 44. En otro sentido parece FAJARDO GARCÍA, G.: cit., pp. 117: "Podría pensarse que la Ley española de economía social ofrece una solución similar al diferenciar por una parte entidades de la economía social por su forma o calificación jurídica (art. 5.1) y por otra, entidades que lo serán porque sus reglas de funcionamiento respondan a los principios de la economía social y estén incluidas en el catálogo (art. 5.2). Pero esta no es una solución satisfactoria; por una parte, porque no todas las entidades cuya forma o calificación jurídica pertenece a alguno de los tipos de entidades de la economía social cumplen siquiera los principios estructurales de la economía social ly la autora menciona aquí expresamente "el caso de centros especiales de empleo que no pertenecen a la economía social por ser propiedad de una entidad pública, de un empresario individual o de una empresa lucrativa], y por otra, porque los principios orientadores de la economía social no recogen sólo rasgos estructurales sino también conductuales cuyo cumplimiento debería poderse demostrar, porque no está vinculado a la forma o calificación jurídica adoptada”. 
- Entidades que tradicionalmente en la literatura española se venían identificando como de economía social: cooperativas; mutualidades; fundaciones; asociaciones que lleven a cabo actividad económica; sociedades laborales; empresas de inserción; centros especiales de empleo, a las que se añaden las cofradías de pescadores, y las sociedades agrarias de transformación. Tales entidades, en cualquier caso, se regularán por sus normas sustantivas específicas (art. 5.3).

- Entidades singulares creadas por normas específicas que respeten los principios orientadores recogidos en el artículo 4 de la Ley.

- Entidades que realicen actividad económica y empresarial y que, respetando los principios orientadores, se incluyan en el catálogo que al efecto llevará el Ministerio de Trabajo e Inmigración, previo informe del Consejo para el Fomento de la Economía Social y en coordinación con las Comunidades Autónomas, conforme al artículo 6 de la Ley.

El tenor literal del precepto nos llevaría a concluir dos cosas que no dejan de ser problemáticas: algunas formas jurídicas serán por Ley entidades de economía social y otras lo serán en la medida en que respondan a los principios que, conforme a la propia Ley, caracterizan a las entidades de economía social ${ }^{22}$.

Las cooperativas, las mutualidades, las fundaciones, las asociaciones, las sociedades laborales, las empresas de inserción, los centros especiales de empleo, las cofradías de pescadores, y las sociedades agrarias de transformación, son siempre entidades de economía social. No se establece, pues, la -en nuestra opinión- conveniente vinculación para la consideración como entidad de economía social con los principios orientadores que se han previsto en el artículo 4. Es cierto que, comúnmente, al definir la economía social a través de sus componentes, general y principalmente, se vienen circunscribiendo, a cuatro familias: Cooperativas, Mutualidades, Asociaciones y Fundaciones, a las que se ha añadido en el caso español las Sociedades Laborales; pero hacerlo legalmente -como se hace en el texto- y sin asegurarnos de alguna manera el respeto de esas -como de otras- formas jurídicas organizativas a los principios y valores propios de la economía social puede terminar banalizando sus rasgos identitarios. En este sentido, con mejor criterio, en sus orígenes el texto propuesto del Grupo de Expertos, después de identificar formas organizativas concretas de economía social, señalaba que lo serían también todas las asociaciones y entidades cuya organización y funcionamiento respondan principalmente a los principios que también. Ahí las características, valores y principios comúnmente aceptados para las yecto de Ley de Economía Social", Noticias de la economía pública social y cooperativa, nº. 54, 2010, p. 56. 
(pp. 55-91)

entidades de economía social pasaban a ser el elemento determinante. Lo que consideramos especialmente oportuno tanto para el caso de las asociaciones como para el resto de las entidades ${ }^{23}$.

Apostar por la necesaria vinculación para la consideración como entidad de economía social con los principios rectores, apostar por las características comunes, y generalmente aceptados en la organización y funcionamiento de las entidades y organizaciones de la economía social, evitaría los peligros que conlleva la atribución, en exclusiva, por la forma jurídica. De igual manera podría así evitarse la instrumentalización de figuras por comportamientos oportunistas y se facilitarían mecanismos más seguros de calificación, cuantificación y control, y quizá se podrían atender legítimas pretensiones de ampliación de las formas de economía social. En efecto, particularmente en los momentos actuales, otras formas jurídicas de organización y de empresas reclaman también su reconocimiento como entidades de economía social, toda vez que contemplan los perfiles o aspectos de la utilidad social que acompaña a las entidades y organizaciones de economía social ${ }^{24}$.

No establecida, formalmente, la vinculación para la consideración como entidad de economía social con los principios orientadores que se han previsto en el artículo 4 y con la pretensión de fin de interés colectivo de sus integrantes y/o de interés general económico o social, voces autorizadas en nuestra doctrina vienen proponiendo interpretaciones que se alejen de la literalidad "Una apreciación atenta a la ratio legis desvelada por una interpretación sistemática y finalista, obliga a excluir de la economía social a aquellos empresarios que el legislador declara que forman parte de la economía social ex art. 5.1 LES si, realmente, no cumplen esa doble exigencia: la finalista de satisfacción del interés de sus miembros o el interés general, o ambos; $y$, la funcional u operativa como es la conformidad sustancial con los principios de la economía social”25.

23. Vid. SÁNCHEZ PACHÓN, L.A.: “El reconocimiento...”, cit., p. 56.

24. Vid. SÁNCHEZ PACHÓN, L.A.: “El reconocimiento...”, cit., p. 56.

25. Vid. PANIAGUA ZURERA, M.: Las empresas de la economía social más allá del comentario a la Ley 5/2011, de economía social, Marcial Pons, Madrid, 2011, p. 166.

También FAJARDO GARCÍA, G.: cit., pp. 110-111: “...la identificación como entidades de economía social de estas organizaciones, atendiendo a su forma o calificación jurídica, plantea la duda de si es suficiente con cumplir este requisito o también serán exigibles los demás (actividad, fines y principios). Solo en el último caso se aclara que las entidades singulares creadas por normas específicas deberán regirse por los principios establecidos en el artículo 4 para ser consideradas entidades de economía social. La respuesta está en el marco jurídico de estas entidades, todas ellas son entidades de derecho privado que pueden desarrollar actividades económico-empresariales y las que lo hagan cumplirán por tanto el primer requisito; todas ellas por definición tienden a satisfacer intereses generales (directamente o en conjunción con los intereses de sus miembros 
Ahora bien, en nuestra opinión, estas propuestas interpretativas sistemáticas y finalistas, reclamadas, por lo demás, por la hermenéutica de nuestro artículo 3 del Código Civil, no autorizan a restringir la consideración como entidades de economía social únicamente -como con frecuencia se hace- a los centros especiales de empleo que "no tengan ánimo de lucro" ${ }^{26}$; limitando esa consideración de entidad de economía social -como se propone recientemente- a lo que hoy se conoce como centros especiales de empleo de iniciativa social ${ }^{27}$.

usuarios) y todas ellas cumplen los principios de la economía social o los persiguen en su actuación, como se puso de manifiesto en el Informe para la Ley de Fomento de la Economía Social".

26. Vid. PANIAGUA ZURERA, M.: op. cit., p. 205. Aunque refiriéndose a lo que entonces era borrador de Anteproyecto de Ley del Ministerio de Trabajo e Inmigración y, con anterioridad el borrador de CEPES, afirma, respecto a los centros especiales de empleo: "Su inclusión dentro del concepto de economía social que diseña el legislador estatal tiene sentido -lo que debe ser enfatizado, pues caben otras opciones- siempre que, conforme a su normativa específica, la titularidad de estos centros especiales de empleo sea privada y no tengan ánimo de lucro. Esta última característica tiene lugar, según su normativa reguladora, cuando se reinvierten todos los posibles beneficios obtenidos en los fines y actividades de los propios centros".

27. Así LÓPEZ PENABAD, M.C., MASIDE SANFIZ, J.M. \& TORRELLLES MANENT, J.: "Análisis económico y social de los centros especiales de empleo: un estudio en Galicia", REVESCO, Revista de estudios Cooperativos, 132, 2019, p. 174: “...no todas las entidades cumplen con sus principios orientadores, los CEE con ánimo de lucro no forman parte de la economía social, y no pueden ser considerados empresas sociales". Conviene advertir que las referencias que ahí se hacen deben matizarse; así MONZÓN CAMPOS, J.L. \& HERRERO MONTAGUD, M.: "Identificación y análisis de las características identitarias de la empresa social europea: aplicación a la realidad de los Centros Especiales de Empleo de la economía espańola, CIRIEC-España, Revista de Economía Pública, Social y Cooperativa, no 87, 2016, p. 322, afirman: Aunque los CEE pueden carecer o no de ánimo de lucro (art. 5/b RD 2273/1985 del Reglamento de los CEE23), los CEE de la ES identificados por las investigaciones del CIRIEC-España verifican los criterios identitarios de la Economía Social, entre ellos el destino prioritario de los beneficios al propósito social.

Por su parte, GARCÍA SABATER, A.B.: cit., 2019, pp. 9-10, viene a señalar que son los CEE lucrativos, que no desarrollan dinámicas ni procesos sociales y su única finalidad es la económica, logrando por medio del empleo protegido obtener beneficios por medio de bonificaciones y subvenciones, los que han hecho "que se mire con recelo a todos los centros, porque desarrollan sus funciones de forma que pueden llegar a considerarse competencia desleal (sic), con empresas ordinarias que contratando trabajadores con discapacidad no perciben tantas ayudas". Más adelante el autor, p. 11, considera -a su juicio- que "una simple lectura de la norma, determina que los CEE mercantiles no son entidades sociales y que por lo tanto están fuera de su ámbito de aplicación, porque no cumplen los principios del art. 4. Las características de primacía de personas sobre el fin social y la reinversión de los resultados, se dan únicamente en los CEE promovidos por entidades sin ánimo de lucro, puesto que las sociedades mercantiles tienen como finalidad generar beneficios no poner en el centro a las personas, y lógicamente reparten los beneficios a sus socios, reinvirtiéndolos únicamente cuando entienden que ello mejorará resultados en ejercicios posteriores. Por lo que parece (sic) que la norma tiene una contradicción interna entre la redacción literal de su artículo quinto y los principios que establece su artículo cuarto". Limitando, también, la consideración de Entidad de Economía social a los CEE sin ánimo de lucro, MARTÍN LORENZO, B.: "Reserva de contratos a los centros especiales de empleo de iniciativa social: régimen jurídico y doctrina consultiva y de los Tribunales Administrativos de recursos contractuales" CIRIEC-España, Revista Jurídica de Economía Social y Cooperativa, no 35, 2019, p. 19. 
(pp. 55-91)

En nuestra literatura, Pablo Moratalla, particularmente, viene defendiendo una nueva forma de enumeración y definición de las entidades y familias que conforman la economía social en España "en la que en relación al sector de empleo protegido únicamente se incluya a los CEEs de iniciativa social por ser las que de manera exclusiva, comparten y ponen en práctica los principios, valores y objetivos fundamentales de la Economía Social" 28 . Considerando que en la actualización y refundición normativa que se hizo en 2013, y que enseguida veremos, "se perdió también una muy buena oportunidad para reforzar y priorizar la labor realizada históricamente por los CEEs sin ánimo de lucro en la creación y mantenimiento de miles y miles de empleos, especialmente, del colectivo de personas con discapacidad con mayores dificultades y necesidades de apoyo (discapacidad intelectual, enfermedad mental, etc. ${ }^{29}$. Proponiendo, en definitiva, una revisión y actualización de la Ley 5/2011, de Economía Social, con el objetivo -se dice- de realizar una adaptación del artículo 5 a la realidad existente en el sector de los Centros Especiales de Empleo, abogando por una nueva enumeración y definición de las entidades y familias que conforman la Economía Social en España, en la que en relación al sector de empleo protegido únicamente se incluya a los CEEs de iniciativa social por ser las que, "de manera exclusiva, comparten y ponen en práctica los principios, valores y objetivos fundamentales de la Economía Social" 30 .

Con todo, en nuestra opinión, hoy por hoy, puede concluirse que el añadido del apartado 4 al artículo 5 de la LES, que se hizo por el artículo 3.1 de la Ley 31/2015, de 9 de septiembre ${ }^{31}$, viene a confirmar que los centros especiales de empleo -sin ulteriores calificativos o caracterizaciones- son entidades de economía social.

28. MORATALLA SANTAMARÍA, P.: cit., pp. 25 y, en p. 31, se marcan como retos y objetivos fundamentales: "Reforzar la posición del sector en el marco de la economía social, buscando una mayor relevancia y reconocimiento institucional como miembros de pleno derecho de la misma. Además..., es necesario seguir impulsando el reconocimiento de los CEE de iniciativa social como los únicos CEES integrantes de la economía social ante otras fórmulas empresariales de empleo protegido ajenas a la propia economía social y a sus principios más fundamentales".

29. MORATALLA SANTAMARÍA, P.: cit., p. 15 "Como se ha comentado, y a pesar de que desde los inicios reguladores del sector se realiza mención expresa a su naturaleza en función del ánimo o no ánimo de lucro, incluso pudiéndose interpretar la posibilidad de regulaciones específicas en función de esta diferencia ..., la realidad es que a lo largo de estos 30 años no ha habido priorización del sector sin ánimo de lucro y de iniciativa social".

30. MORATALLA SANTAMARÍA, P.: cit., pp. 24 y 25.

31. Artículo 5. Entidades de la economía social....

...

4. Se declaran entidades prestadoras de Servicios de Interés Económico General, los Centros Especiales de Empleo y las Empresas de Inserción, constituidas y calificadas como tales según su normativa reguladora. Asimismo, podrá 
Los centros especiales de empleo forman parte así de las entidades de economía social. Es cierto que los centros especiales de empleo, conforme a la configuración que hemos visto en la LISMI y que se mantiene, como veremos, en el actual Real Decreto Legislativo 1/2013, de 29 de noviembre, carecen de personalidad jurídica. Y es cierto que el elemento de atribución de la personalidad jurídica es esencial para que el Derecho tome en consideración una organización económica con propia entidad, porque solo los sujetos -personas físicas o jurídicas- pueden ser titulares de derechos y obligaciones, pero ello no impide que el legislador pueda conectar ciertos efectos (medidas de protección, responsabilidades, obligaciones) en el ejercicio de actividades caracterizadas de economía social a organizaciones, grupos, sectores o ramas de actividad empresarial sin entidad jurídica propia, sin perjuicio de que la titularidad de aquellos efectos tenga que ser atribuida finalmente a los correspondientes tipos de sujetos o entidades con personalidad jurídica propia ${ }^{32}$. En definitiva, y como se ha podido decir, la forma jurídica opera en un plano distinto al de su consideración como entidad de economía social ${ }^{33}$. Aquí, el concepto de entidad no se corresponde necesariamente con la personalidad jurídica ${ }^{34}$.

extenderse esta declaración a cualesquiera otras entidades de la economía social que tengan por objeto igualmente la inserción laboral de colectivos en riesgo de exclusión, conforme a lo que se establezca reglamentariamente.

Este reconocimiento, se viene a decir en el Preámbulo de la Ley 31/2015, supone que las subvenciones concedidas a estas entidades quedaran sometidas ahora al Reglamento 360/2012 de la Comisión, de 25 de abril de 2012, y puedan alcanzar los $500.000 €$ en un período de tres años cuando hasta la fecha el máximo era de $200.000 €$ en el mismo periodo de tiempo.

Se trata, además, de una declaración respaldada por la propia Comisión Europea, que considera la inclusión social y laboral como un Servicio de Interés Económico General, y estas entidades son las que centran precisamente su actividad en los colectivos más desfavorecidos y en torno al concepto del empleo protegido.

32. Vid. SÁNCHEZ PACHÓN, L.A.: "La delimitación de las entidades y organizaciones de economía social en la próxima ley reguladora del sector", CIRIEC-España, Revista de Economía Pública, Social y Cooperativa, no. 66, 2009, p. 69.

33. Vid. RONCERO SÁNCHEZ, A.: "Importancia económica, régimen legal y características propias de las cooperativas agrarias y de las sociedades agrarias de transformación”. En Cooperativas agrarias y sociedades agrarias de transformación, (PULGAR EZQUERRA, J. (Dir.) y VARGAS VASSEROT, C. (Coord.)), Dykison, Madrid, 2006, p. 31, respecto a las entidades mercantiles y SAT.

34. Vid. FAJARDO GARCÍA, G.: cit., p. 110, nota núm. 41, donde resalta que ya destacó el Comité Económico y Social Europeo que en la definición de la economía social ha de ponerse el acento en su organización formal y no en su personalidad jurídica, que puede tener o no. 


\section{El Real Decreto Legislativo 1/2013 de texto refundido de la ley general de las personas con discapacidad y de su inclusión laboral}

El Real Decreto Legislativo 1/2013, de 29 de noviembre, por el que se aprueba el Texto Refundido de la ley general de derechos de las personas con discapacidad y de su inclusión social (BOE de 3 de diciembre de 2013), refunde y deroga la Ley 13/1982, de 7 de abril, de integración social de las personas con discapacidad, la Ley 51/2003, de 2 de diciembre, de igualdad de oportunidades, no discriminación y accesibilidad universal de las personas con discapacidad, y la Ley 49/2007, de 26 de diciembre, de infracciones y sanciones en materia de igualdad de oportunidades no discriminación y accesibilidad universal de las personas con discapacidad. La base normativa para ello es la Disposición final segunda de la Ley 26/2011, de 1 de agosto de 26 de diciembre (modificada por la disposición final 5 de la Ley 12/2012), de adaptación normativa a la Convención Internacional sobre los derechos de las personas con discapacidad ${ }^{35}$. Como se ha venido a decir, se hacía necesaria la armonización, aclaración y refundición de las tres leyes, a fin de reconocer a las personas con discapacidad como sujetos titulares de derechos estando los poderes públicos obligados a garantizar el ejercicio de los mismos ${ }^{36}$.

La Convención Internacional sobre los derechos de las personas con discapacidad, hecha en Nueva York, el 13 de diciembre dc 2006, fue ratificada por España mediante Instrumento de ratificación publicado el 21 de abril de 2008, y a ella se encuentra vinculada la Unión Europea, mediante Decisión 2010/48/CE, del Consejo, de 26 de noviembre de 2009 (DO L 23, de 27 de enero de 2010). Su artículo 27 recoge que los Estados Partes reconocen el derecho de las personas con discapacidad a trabajar, en igualdad de condiciones con las demás; ello incluye el derecho a tener la oportunidad de ganarse la vida mediante un trabajo libremente elegido o aceptado en un mercado y un entorno laborales que sean abiertos, inclusivos y accesibles a las

35. Disposición final segunda. Autorización al Gobierno para la refundición de textos legales.

El Gobierno elaborará y aprobará antes del 31 de diciembre de 2013 y previa consulta al Consejo Nacional de la Discapacidad, un Texto Refundido en el que se regularicen, aclaren y armonicen la Ley 13/1982, de 7 de abril, de integración social de los minusválidos, la Ley 51/2003, de 2 de diciembre, de igualdad de oportunidades, no discriminación y accesibilidad universal de las personas con discapacidad y la Ley 49/2007, de 26 de diciembre, de infracciones y sanciones en materia de igualdad de oportunidades, no discriminación y accesibilidad universal de las personas con discapacidad.

36. MORATALLA SANTAMARÍA, P.: cit., p. 5, si bien, el autor considera que "se perdió una muy buena oportunidad para, en el proceso de refundición y en el área de integración socio-laboral, actualizar y mejorar algunos de los enfoques, medidas y acciones reguladas" (con cita de Muñoz García, C.: "La Ley General de derechos de las personas con discapacidad y de su inclusión socio-laboral”, La Ley, no . 8231, 2 de enero, 2014. 
personas con discapacidad. Los Estados parte salvaguardarán y promoverán el ejercicio del derecho al trabajo... adoptando medidas pertinentes, incluida la promulgación de legislación, entre ellas:

f) Promover oportunidades empresariales, de empleo por cuenta propia, de constitución de cooperativas y de inicio de empresas propias;

g) Emplear a personas con discapacidad en el sector público;

h) Promover el empleo de personas con discapacidad en el sector privado mediante politicas y medidas pertinentes, que pueden incluir programas de acción afirmati$v a$, incentivos y otras medidas;

i) Velar por que se realicen ajustes razonables para las personas con discapacidad en el lugar de trabajo;

j) Promover la adquisición por las personas con discapacidad de experiencia laboral en el mercado de trabajo abierto;

k) Promover programas de rehabilitación vocacional y profesional, mantenimiento del empleo y reincorporación al trabajo dirigidos a personas con discapacidad.

Será ahora el artículo 43 de este Texto Refundido el que recoja la configuración de los $\mathrm{CEE}^{37}$. Con arreglo a lo dispuesto, principalmente en ese y otros artículos del Real Decreto Legislativo y conforme, también, a lo que se establece en el Reglamen-

37. Artículo 43. Centros especiales de empleo para la inclusión laboral de las personas con discapacidad.

1. Los centros especiales de empleo son aquellos cuyo objetivo principal es el de realizar una actividad productiva de bienes o de servicios, participando regularmente en las operaciones del mercado, y tienen como finalidad el asegurar un empleo remunerado para las personas con discapacidad; a la vez que son un medio de inclusión del mayor número de estas personas en el régimen de empleo ordinario. Igualmente, los centros especiales de empleo deberán prestar, a través de las unidades de apoyo, los servicios de ajuste personal y social que requieran las personas trabajadoras con discapacidad, según sus circunstancias y conforme a lo que se determine reglamentariamente.

2. La plantilla de los centros especiales de empleo estará constituida por el mayor número de personas trabajadoras con discapacidad que permita la naturaleza del proceso productivo y, en todo caso, por el 70 por 100 de aquélla. A estos efectos no se contemplará el personal sin discapacidad dedicado a la prestación de servicios de ajuste personal y social.

Se entenderán por servicios de ajuste personal y social los que permitan ayudar a superar las barreras, obstáculos o dificultades que las personas trabajadoras con discapacidad de los centros especiales de empleo tengan en el proceso de incorporación a un puesto de trabajo, así como en la permanencia y progresión en el mismo. Igualmente se encontrarán comprendidos aquellos dirigidos a la inclusión social, cultural y deportiva.

3. La relación laboral de los trabajadores con discapacidad que presten sus servicios en los centros especiales de empleo es de carácter especial, conforme al artículo 2.1.g) de Texto Refundido de la Ley del Estatuto de los Trabajadores, aprobado por Real Decreto Legislativo 1/1995, de 24 de marzo, y se rige por su normativa especifica. 
to en vigor, las características más relevantes de los CEE podemos resumirlas de la siguiente manera ${ }^{38}$ :

- Los CEE son agrupaciones productivas de bienes o servicios, pudiendo pertenecer a cualquier tipo de entidad, pública o privada ${ }^{39}$.

- La actividad se realiza de forma profesional y habitual, estando dirigida al mercado ("participando regularmente en las operaciones de mercado"), pudiendo tener o no ánimo de lucro ${ }^{40}$. Será, pues, la aplicación de sus posibles beneficios al propio objeto social y a la propia entidad la que permite la diferenciación. Esto ha propiciado que, particularmente, en el sector de la Economía Social se hayan ido diferenciando dos sectores: CEEs de la iniciativa social pública, sin ánimo de lucro, y CEEs del sector privado con ánimo de lucro; los primeros -se dice- agrupan

38. Con mayor detalle puede verse, CAVAS MARTÍNEZ, F. \& GRIMALDOS GARCÍA, M.: cit., pp. 174177. Vid., también, AA.VV.: Libro Blanco del cooperativismo y la economía social valenciana, Rafael Chaves Ávila, Juan Francisco Juliá Igual y José Luis Monzón Campos (dirs.), CIRIEC- España, Valencia, 2019, p. 179, los autores aquí resumen en cuatro las características de los CEE que, sintéticamente, serían:

-Objetivo principal es una actividad productiva de bienes y servicios en el mercado.

-Finalidad de asegurar el empleo remunerado de las personas con discapacidad para su inclusión en el empleo ordinario.

-Proporcionar a través de las unidades de apoyo servicios de ajunte

-Constituidos mayoritariamente por trabajadores con discapacidad, al menos, $70 \%$.

39. El artículo 45 del Real Decreto Legislativo dispone:

Artículo 45. Creación de centros especiales de empleo para la inclusión laboral de las personas con discapacidad.

1. Los centros especiales de empleo podrán ser creados tanto por organismos públicos y privados como por las empresas, siempre con sujeción a las normas legales, reglamentarias y convencionales que regulen las condiciones de trabajo. Por su parte, el artículo 6 del Reglamento dispone:

Art. 6.

Los Centros Especiales de Empleo podrán ser creados por las Administraciones Públicas, bien directamente o en colaboración con otros organismos, por Entidades, o por personas fisicas, jurídicas o comunidades de bienes que tengan capacidad jurídica y de obrar para ser empresarios, conforme a lo señalado en el artículo 2.2 en relación con el artículo 3. ${ }^{\circ}$ del Real Decreto 1368/1985, de 17 de julio, por el que se regula la relación laboral de carácter especial de los minusválidos que trabajen en los Centros Especiales de Empleo.

Y el Art. 9. Los Centros Especiales de Empleo vendrán obligados a realizar una gestión sujeta a las mismas normas y requisitos que los que afectan a cualquier Empresa del sector a que pertenezcan.

40. Art. 5, del Reglamento

a) Según su titularidad, los Centros Especiales de Empleo podrán tener carácter público o privado.

b) Atendiendo a la aplicación de sus posibles beneficios, los Centros podrán carecer o no de ánimo de lucro, según que aquellos repercutan en su totalidad en la propia institución o se aproveche parte de ellos en otra finalidad distinta que haya de cubrir la Entidad titular del mismo. 
del entorno del $51 \%$ de todos los CEEs y prácticamente el 60\% de las personas con discapacidad en empleo protegido ${ }^{41}$.

No obstante, no podrán ser CEE los de Educación Especial que dispongan de aulas o talleres para el aprendizaje profesional de los minusválidos en ellos integrados $^{42}$.

- Los CEE son un medio de inclusión de las personas con discapacidad en el régimen de empleo ordinario. El trabajo que en ellos se desarrolla es remunerado con contrato de relación laboral especial; lo que les diferencia de los "Centros Ocupacionales", que son de asistencia y rehabilitación.

- Los CEE ofrecen servicios de ajuste personal y social a través de las "unidades de apoyo".

- El empleo que ofrecen es "protegido" (así lo rotula la Sección $3^{a}$ del VI ${ }^{43}$ ), porque está apoyado por técnicos o monitores que puede acompañar a los trabajadores, cuenta con medidas de fomento superiores a las recibida por las empresas ordinarias, y el acceso o permanencia de los trabajadores con discapacidad en el CEE elude total o parcialmente la concurrencia con los demás trabajadores.

- Como mínimo el 70\% de la plantilla serán personas con discapacidad, si bien en ese porcentaje no se incluye el personal sin discapacidad dedicado a la prestación de servicios de ajuste personal y social.

- Los CEE pueden servir como tránsito hacia el mercado de trabajo ordinario, a través de los "enclaves laborales", previstos en el artículo $46^{44}$.

41. Vid. MORATALLA SANTAMARÍA, P.: cit., p. 15, y proponiendo la reforma de la Ley de Economía Social para que solo los CEE de iniciativa social y sin ánimo de lucro puedan tener la consideración de Entidad de Economía social, pp. 20 y 24. Sobre esta tipología, vid, también MONZÓN CAMPOS, J.L. \& HERRERO MONTAGUD, M.: cit., p. 319, conforme al estudio realizado en 2014.

42. Art. 4. del Reglamento

En ningún caso tendrán la consideración de Centros Especiales de Empleo los Centros Ocupacionales definidos en el artículo 53 de la Ley 13/1982, de 7 de abril, de integración social de los minusválidos [hoy artículo 52 del Real Decreto Legislativo 1/2013], ni los Centros reconocidos de Educación Especial que dispongan de aulas o talleres para el aprendizaje profesional de los minusválidos en ellos integrados.

43. Sobre los diferentes tipos de empleo, dispone el artículo 37.2: Las personas con discapacidad pueden ejercer su derecho al trabajo a través de los siguientes tipos de empleo: a) Empleo ordinario, en las empresas y en las administraciones públicas, incluido los servicios de empleo con apoyo. b) Empleo protegido, en centros especiales de empleo y en enclaves laborales. c) Empleo autónomo.

44. Articulo 46. Enclaves laborales. Para facilitar la transición al empleo ordinario de las personas trabajadoras con discapacidad con especiales dificultades para el acceso al mismo, se pueden constituir enclaves laborales, cuyas características y condiciones se establecen reglamentariamente. 
Con todos estos datos se ha podido afirmar que nuestro ordenamiento jurídico no establece ninguna limitación respecto de la naturaleza pública y privada, forma societaria, ánimo de lucro (o no), o titularidad del capital social de los entes que pueden constituir un CEE. A fin de potenciar su creación -se dice- el legislador trata de imponer las mínimas restricciones posibles en este sentido. El legislador pretende que el CEE sea y funcione como una empresa normal. Únicamente se requiere que sea calificado como CEE por la Administración competente e inscrito en el correspondiente Registro de Centros Especiales de Empleo ${ }^{45}$.

\section{Incidencia de Ley de Contratos del Sector Público (Ley 9/2017, de 8 de noviembre) en los centros especiales de empleo y su problemática}

Ley 9/2017, de 8 de noviembre, de Contratos del Sector Público, por la que se transponen al ordenamiento jurídico español las Directivas del Parlamento Europeo y del Consejo 2014/23/UE y 2014/24/UE, de 26 de febrero de 2014, declara en su Preámbulo $(\mathrm{V})$ que "Respecto de los temas sociales, se siguen regulando los contratos reservados a centros especiales de empleo o la posibilidad de reservar su ejecución en el marco de programas de empleo protegido, extendiéndose dicha reserva a las empresas de inserción y exigiéndoles a todas las entidades citadas que tengan en plantilla el porcentaje de trabajadores discapacitados que se establezca en su respectiva regulación...”.

Su artículo 99. 4 dispone que "Cuando el órgano de contratación proceda a la división en lotes del objeto del contrato, este podrá introducir las siguientes limitaciones, justificándolas debidamente en el expediente... Podrá reservar alguno o algunos de los lotes para Centros Especiales de Empleo o para empresas de inserción, o un porcentaje minimo de reserva de la ejecución de estos contratos en el marco de programas de empleo protegido, de conformidad con lo dispuesto en la Disposición adicional cuarta. Igualmente se podrán reservar lotes a favor de las entidades a que se refiere la Disposición adicional cuadragésima octava, en las condiciones establecidas en la citada disposición".

La norma no determina expresamente que dichos CEE deban ser de iniciativa social, no obstante -se ha dicho- debe entenderse que ha de ser así interpretado, pues la Disposición Adicional Cuarta titulada "Reserva de contratos" a la que se remite expresamente el art. 99, sólo hace mención a los centros de iniciativa social. En este 
Sentido se ha manifestado el Tribunal Administrativo Central de Recursos Contractuales TACRC en su Resolución no 510/2019 y refuerza dicha interpretación que en ambos artículos se menciona de forma conjunta a los CEE y a las empresas de inserción, que sólo pueden ser de iniciativa social ${ }^{46}$.

Esa Disposición adicional cuarta de la Ley 9/2017, refiriéndose a los contratos reservados, viene a recoger que Mediante Acuerdo del Consejo de Ministros o del órgano competente en el ámbito de las Comunidades Autónomas y de las Entidades Locales, se fijarán porcentajes minimos de reserva del derecho a participar en los procedimientos de adjudicación de determinados contratos o de determinados lotes de los mismos a Centros Especiales de Empleo de iniciativa social ... a condición de que el porcentaje de trabajadores con discapacidad o en situación de exclusión social de los Centros Especiales de Empleo... al menos del 30 por 100.

Ese Acuerdo de Consejo de Ministros, se recoge también, debería adoptarse en el plazo máximo de un año a contar desde la entrada en vigor de esta Ley. Transcurrido este plazo sin haberse adoptado, "los órganos de contratación del sector público estatal deberán aplicar el porcentaje mínimo de reserva de 7 por ciento, que se incrementará hasta un 10 por ciento a los cuatro años de la entrada en vigor de esta Ley, sobre el importe global de los procedimientos de adjudicación de suministros y servicios incluidos en los códigos $C P V \ldots{ }^{\text {"'A7 }}$.

La Orden PCI/566/2019, de 21 de mayo (BOE del 25), por la que se publica el Acuerdo del Consejo de Ministros de 12 de abril de 2019, por el que se aprueba el Plan para el impulso de la contratación pública socialmente responsable en el marco de la Ley 9/2017, de 8 de noviembre, de Contratos del Sector Público, por la que se transponen al ordenamiento jurídico español las Directivas del Parlamento Europeo y del Consejo 2014/23/UE y 2014/24/UE, de 26 de febrero de 2014, mantiene los porcentajes de la Ley $9 / 2017$.

Se ha puesto en evidencia que, así como para el caso de que no haya acuerdo de Consejo de Ministros, en la contratación del sector público estatal se aplicarán los porcentajes subsidiarios, no hay, sin embargo, consecuencia legal alguna ante la falta de acuerdo por parte de los órganos competentes en la administración autonómica y local, lo que para el autor resulta incomprensible ${ }^{48}$.

46. Vid. GARCÍA SABATER, A.B.: cit., p. 16.

47. Vid. ANDRÉS PÉREZ, Ma del R.: "Los contratos reservados en la ley 9/2017, del 8 de noviembre”. Observatorio Contratación Pública, http://www.obcp.es/index.php/mod.opiniones/mem.detalle/id.337/relcategoria.208/relmenu.3/chk.0a06bb42570ad5fa570d9459e03828fc, 2018.

48. Vid. GARCÍA SABATER, A.B.: cit., p. 17. Sobre los ya numerosos acuerdos que han adoptado las administraciones públicas, vid. BURZACO SAMPER, M.: "Concurrencia competitiva, igualdad entre licitadores 
Conforme a aquella Disposición adicional cuarta de la Ley 9/2017, adquieren carta de naturaleza los Centros Especiales de Empleo de iniciativa social, que van a ser conceptuados mediante un nuevo apartado 4 que, mediante la Disposición final 14 de la Ley 9/2017, se va a ańadir al artículo 43 del Real Decreto Legislativo 1/2013:

Artículo 43. Centros especiales de empleo para la inclusión laboral de las personas con discapacidad.

(...)

4. Tendrán la consideración de Centros Especiales de Empleo de iniciativa social aquellos que cumpliendo los requisitos que se establecen en los apartados $1 .^{\circ}$ y $2 .^{\circ}$ de este artículo son promovidos y participados en más de un 50 por ciento, directa o indirectamente, por una o varias entidades, ya sean públicas o privadas, que no tengan ánimo de lucro o que tengan reconocido su carácter social en sus Estatutos, ya sean asociaciones, fundaciones, corporaciones de derecho público, cooperativas de iniciativa social u otras entidades de la economía social, así como también aquellos cuya titularidad corresponde a sociedades mercantiles en las que la mayoría de su capital social sea propiedad de alguna de las entidades señaladas anteriormente, ya sea de forma directa o bien indirecta a través del concepto de sociedad dominante regulado en el artículo 42 del Código de Comercio, y siempre que en todos los casos en sus Estatutos o en acuerdo social se obliguen a la reinversión integra de sus beneficios para creación de oportunidades de empleo para personas con discapacidad y la mejora continua de su competitividad y de su actividad de economía social, teniendo en todo caso la facultad de optar por reinvertirlos en el propio centro especial de empleo o en otros centros especiales de empleo de iniciativa social.

El texto no puede decirse que tenga muchas virtudes, genera bastantes interrogantes y, en nuestra opinión, no responde a la mejor técnica legislativa ${ }^{49}$. Si se quería crear una nueva categoría de centros especiales de empleo, vinculados a la Economía Social, la coherencia del sistema reclamaría que se hubiera modificado también la Ley de Economía Social, y esto no se ha hecho. Por otra parte, la decisión político-jurídica de limitar la reserva de la contratación pública a un determinado tipo de centros espe-

y discriminación positiva en las reservas de contratos: un análisis desde los conflictos", CIRIEC-España, Revista Jurídica de Economía Social y Cooperativa, no 35, 2019, p. 12 y referencias ahí indicadas.

49. Distinto es el parecer de CALVO VÉRGEZ, J.: "La proyección de la nueva Ley 9/2017, de 8 de noviembre, de Contratos del sector público, sobre el ámbito de la Economía social: un nuevo marco regulatorio para las entidades del tercer sector", Revista Aranzadi Doctrinal, núm. 4, 2019, p. 12, considerando que "se ha mejorado de manera sustancial su definición y exigencias de la ley". 
ciales de empleo no deja de ser polémica y, prueba de ello, son los tempranos recursos interpuestos contra las licitaciones que impiden concurrir a cualquier tipo de CEE.

Al respecto, puede consultarse la Resolución 100/2018 del Órgano Administrativo de Recursos Contractuales de Euskadi, resolviendo el recurso que pretendía eliminar la exigencia de "iniciativa social” en el Pliego de cláusulas administrativas particulares. El recurrente esgrimía que el contenido del pliego podría suponer una vulneración del ordenamiento jurídico de la Unión Europea al imponer una discriminación entre operadores económicos (el artículo 20 de la Directiva 2014/20/UE, únicamente hace referencia a la finalidad de empleo de las personas con discapacidad y a un mínimo de $30 \%$ de personas con discapacidad sin que haga mención a limitaciones adicionales, como la exigencia de reinversión o que deba ser «de iniciativa social»). En la Resolución se concluye -en nuestra opinión sin fundamentación suficiente- que es correcta la reserva del contrato a un tipo concreto de Centros Especiales de Empleo -los de iniciativa social, en detrimento de los de iniciativa empresarial-, porque "el legislador goza de un margen de discrecionalidad a la hora de definir y concretar en el derecho interno lo que se entenderá por "operadores económicos cuyo objetivo principal sea la integración social y profesional de personas discapacitadas o desfavorecidas", sin que pueda entenderse que artículo 20 de la Directiva 2014/24/UE establece un mandato claro e incondicionado que impida cualquier tipo de interpretación o adaptación ${ }^{50}$.

En el mismo sentido puede citarse, también, la Resolución del Tribunal Administrativo Central de Recursos Contractuales 860/2018, de 1 de octubre de 2018. El recurrente esgrimía que una interpretación más restrictiva del artículo 20 de la Directiva 2014/24/UE, provocaba "un daño directo a la libre competencia, interdicción de la no discriminación y, facilitando el fraude en la contratación del sector público" 51 . El órgano administrativo afirmó que el artículo de la Directiva carece de efecto directo al no contener un mandato claro e incondicionado y que los Estados miembros gozan de libertad para cumplir el mandato dado desde el acervo comunitario que no es otro, que el de reservar licitaciones de determinados contratos a favor de operadores económicos que desempeñan una función social. Por ello, se ha podido decir, el legislador estatal ha añadido a los CEE el calificativo de ser de iniciativa social ${ }^{52}$.

50. Vid. sobre la misma, BURZACO SAMPER, M.: cit., pp. 18 y ss.

51. Sobre la misma y la núm. 914/2018, de 11 de octubre de 2018, vid. GARCÍA SABATER, A.B.: cit. p. 17; también MARTÍN LORENZO, B.: cit., pp. 22 y 27.

52. Vid. ANGULO GARZARO, A.: "La transposición del artículo 20 de la Directiva 2014/24/UE a la Ley de contratos del sector público (LCSP) y su incidencia en la competencia. Especial referencia a los centros especiales de empleo de iniciativa social”, Revista Aranzadi Unión Europea, núm. 3, 2019, p. 3. 
(pp. 55-91)

Uno de los argumentos que más se ha utilizado contra las reservas de contratos es la limitación a la libre competencia que suponen. Restringiendo la posibilidad de participar a los CEE y a las empresas de inserción, buena parte del tejido productivo puede quedar fuera de ese tipo de licitaciones. Si, además, la restricción beneficia un tipo de CEE sobre otro, la discriminación tiene aún mayores dificultades de justificación.

Algunos autores consideran, sin embargo, que existe una justificación social detrás de esta tipología de licitación que reconoce la LCSP mediante la excepción a la no discriminación por tipo de empresa que recoge en su artículo 132. "Para medir el grado de competencia -se dice- se ha usado como variable el número de empresas que han presentado ofertas de cada licitación. Los casos donde se presenta única oferta no alcanzan el 50\%, aunque sí suponen la mayoría. En más de un 25\% de las licitaciones se han presentado tres o más ofertas. Por lo tanto -añaden- no puede afirmarse que los contratos reservados se constituyan en una suerte de contrato de adjudicación directa para los CEE y las Empresas de inserción, puesto que como ponen de manifiesto los datos, en una mayoría de los casos analizados existen al menos dos ofertas que compiten entre sîn'53.

En cualquier caso es necesario seńalar que la posibilidad de excepcionar las reglas de concurrencia propias de la contratación pública en favor de entidades sin ánimo de lucro, tiene el respaldo en la jurisprudencia del Tribunal de Justicia de la Unión Europea (TJUE), en diversas sentencias ${ }^{54}$.

Con todo, no deja de ser tampoco conflictivo el trato diferenciado de los centros especiales de empleo de iniciativa privada frente a los de iniciativa social en determinados aspectos o condiciones laborales, que, no obstante, se ve confirmado con la Sentencia de la Sala de lo Social de la Audiencia Nacional del 14 de noviembre de 2019, que desestima en su integridad la impugnación de la Confederación Nacional

53. Vid. MENDOZA JIMÉNEZ, J., ROMÁN CERVANTES, C. \& HERNÁNDEZ LÓPEZ, M.: "La economía social...", cit., p. 235. También en "Los contratos reservados: una herramienta para el fortalecimiento de las entidades sociales", CIRIEC-España, Revista Jurídica de Economía Social y Cooperativa, no 33, pp. 322 y ss., los autores comentan dos Resoluciones del Tribunal Administrativo de Contratos Públicos de Aragón. En cuanto a la supuesta disminución de la libre competencia, el Tribunal da un espaldarazo a los contratos reservados como instrumento de contratación pública responsable al razonar que: "El principio de apertura a la competencia, puede y debe ser limitado sobre la base de razones de interés general, como la protección del medio ambiente, la salud pública, o, como en este caso, la inserción laboral de personas con dificultades de acceso al mercado de trabajo, siempre que estas actuaciones sean proporcionadas y no vulneren el principio de igualdad de trato".

54. Vid. MARTÍN LORENZO, B.: cit., pp. 9-10; BURZACO SAMPER, M.: cit. p. 16. 
de Centros Especiales de Empleo (CONACEE) contra el XV Convenio Colectivo general de centros y servicios de atención a personas con discapacidad ${ }^{55}$.

Se impugnaba el XV Convenio Colectivo general de centros y servicios de atención a personas con discapacidad, porque incluyó en su ámbito funcional a los centros especiales de empleo, aunque no se firmó por las asociaciones que encuadran dichos centros. La Audiencia desestima dicha pretensión dado que es un convenio sectorial, que incluyó en su ámbito a los CEE durante cinco convenios sectoriales y se suscribió por la mayoría de su comisión negociadora, sin que haya una pérdida sobrevenida de legitimidad por el hecho de que no firmen el convenio algunas asociaciones minoritarias. Se impugna también el art. 29.2 del convenio, porque distingue salarialmente los CEE de iniciativa social y económica, desestimándose también dicha pretensión porque -se dice- se trata de centros distintos que, si bien comparten fines, medios y porcentaje de personas con discapacidad, se trata de supuestos totalmente desiguales, porque los CEE de iniciativa social no tienen afán de lucro y reinvierten todos sus beneficios en la consecución de sus fines, y los CEE de iniciativa económica tienen también por objeto lograr los máximos beneficios para sus dueños.

La Sentencia ha sido valorada positivamente por la Federación Empresarial Española de Asociaciones de Centros Especiales de Empleo (FEACEM), porque -se dice- avala y justifica plenamente la diferenciación entre centros especiales de empleo de iniciativa social y los centros especiales de empleo de iniciativa empresarial con base en sus distintas finalidades y, por tanto -entienden- la posibilidad de trato diferenciado entre ambas figuras ${ }^{56}$.

Para configurar los CEE de iniciativa social, el nuevo apartado 4 añadido al artículo 43 del Real Decreto Legislativo 1/2013, requiere que los CEE ordinarios (que cumplen con los apartados $1 .^{\circ}$ y $2 .^{\circ}$ del mismo artículo 43) se encuentren en alguno de los siguientes supuestos, que no dejan de ser confusos:

- Estén promovidos y participados en más de un 50 por ciento, directa o indirectamente, por una o varias entidades, ya sean públicas o privadas, que no tengan

55. Puede verse en http://www.cermicantabria.org/images/pdf/2019/Sentencia_135-20193.pdf

56. El presidente de FEACEN, Daniel-Aníbal García, declaró que "es muy importante esta sentencia al ponerse de manifiesto, como ya hizo el Tribunal Supremo, que las dos realidades no somos iguales. La sentencia pone de relieve que los Centros Especiales de Empleo de Iniciativa Social tienen un beneficio social mucho mayor que los centros especiales de empleo con ánimo de lucro; a nosotros solo nos mueve la creación de oportunidades de empleo para personas con discapacidad y la mejora continua de nuestra actividad, que es genuinamente economía social; mientras que a la otra realidad le mueve la búsqueda del mayor lucro económico posible" http://www.diariosigloxxi.com/texto-s/mostrar/341663/feacem-valora-positivamente-sentencia-audiencia-nacional-sobre-centros-especiales-empleo 
(pp. 55-91)

ánimo de lucro o que tengan reconocido su carácter social en sus Estatutos. Y se citan, a título de ejemplo "asociaciones, fundaciones, corporaciones de derecho público, cooperativas de iniciativa social u otras entidades de la economía social". No se aclara en qué consiste la promoción, ni tampoco el modo de participación "indirecta" de las entidades. Además, no deja de ser curiosa la disyuntiva que se presenta a estas entidades titulares de los CEE: pueden no tener ánimo de lucro o -teniéndolo- bastará que tengan reconocido en sus estatutos su carácter social ${ }^{57}$. Y, por otra parte, sorprende que se citen como ejemplos algunas entidades de economía social (asociaciones, fundaciones y cooperativas, pero solo un tipo de éstas) y "otras entidades de economía social", con lo que parece ignorar la misma Ley 5/2011 de Economía Social y, particularmente, sus artículo 5.

- Pueden ser también CEE de iniciativa social aquellos cuya titularidad corresponde a sociedades mercantiles en las que la mayoría de su capital social sea propiedad de alguna de las entidades mencionadas anteriormente; es decir, entidades de economía social o que no tengan ánimo de lucro o que tengan reconocido su carácter social en sus Estatutos, pero se añade, ya sea de forma directa o bien indirecta a través del concepto de sociedad dominante regulado en el artículo 42 del Código de Comercio y siempre que en todos los casos en sus Estatutos o en acuerdo social se obliguen a la reinversión integra de sus beneficios para creación de oportunidades de empleo para personas con discapacidad...

Con absoluta imprecisión el texto apunta a una propiedad "indirecta", cuando parece que quiere referirse al "control", que es el concepto que utiliza el Código de Comercio para poder definir el grupo ${ }^{58}$, pero olvida, además, que el concepto de grupo del artículo 42 del Código de Comercio es el grupo "societario", y aquí parece querer reconocerse la existencia de un grupo en el que el control pudiera provenir de una entidad no societaria.

Por otra parte la exigencia, en todo caso, de que en los estatutos "o el acuerdo social" (sic) de la -según parece- sociedad mercantil titular del CEE se obliguen a la reinversión íntegra de sus beneficios, hace inviable, particularmente para las sociedades mercantiles de capital (artículos 93.a y 238 bis de la Ley de Sociedades de Capital), la titularidad de estos CEE de iniciativa social.

57. Esa declaración, señala GARCÍA SABATER, A.B.: cit., p. 13, "permitiría simular que se encuentra, ficticiamente, dentro de los principios orientadores de la Ley 5/2011”.

58. Vid. CABANA TENA, A.: El concepto de grupo de sociedades, Tirant lo Blanch. Valencia, 2019, pp. 188 y ss. 
Todo parece indicar que, al configurar los CEE de iniciativa social, la idea de nuestro legislador, era sumarse al sector doctrinal y de la economía social que vine proponiendo la diferenciación de los $\mathrm{CEE}^{59}$; reservando la consideración de $\mathrm{CEE}$ de iniciativa social a aquellos CEE cuya titularidad corresponde a entidades públicas o privadas de carácter no lucrativo o a entidades públicas o privadas que están participadas mayoritariamente en su capital social, de manera directa o indirecta, por entidades sin ánimo de lucro o entidades de economía social y que reinvierten sus beneficios al fin social de la entidad ${ }^{60}$. Si esa era el propósito del legislador, con independencia de que se comparta o no esa corriente ${ }^{61}$, lo cierto es que la configuración legal de los CEE de iniciativa social no se hace bien (al margen de que hubiera reclamado también la reforma de la Ley 5/2011 de Economía Social), genera más confusión que aclara, (particularmente los que se encuentran en el segundo de los supuestos que antes mencionamos) y, en la práctica, terminará limitando los CEE de iniciativa social a aquellos que estén promovidos y participados en más de un 50 por ciento, directa o indirectamente, por una o varias entidades, ya sean públicas o privadas, que no tengan ánimo de lucro o que tengan reconocido su carácter social

59. Vid. AA.VV.: cit., pp. 179-181, los autores recogen una clasificación del Ministerio de Empleo y Seguridad Social que distingue entre Centros de Iniciativa Social (CEEIS) y Centros de Iniciativa Capitalista (CEEIC). Así, en 2013 habría, a nivel nacional, 617 CEEIS y 1152 CEEIC, (proporciones similares para las cifras de 2015, según datos del Gobierno, puede verse http://www.congreso.es/112p/e3/e_0036553_n_000. pdf ) y en el año 2017, 714 CEEIS y 1391 CEEIC. La Asociación CIRIEC-España, apuesta por una distinción matizada, distinguiendo los CEE de Economía Social (CEE ES) y CEE de la Economía Capitalista (CEE EC). En esta clasificación, los CEE de Economía Social englobarían a los siguientes:

- CEE calificados como de Iniciativa Social por la Ley 9/2017, de Contratos del Sector Público.

- Centros dependientes de entidades religiosas con personalidad jurídica específica.

- Centros no incluidos en el punto uno con personalidad jurídica de cooperativa o identificados como sociedades laborales.

- CEE incluidos en la base de datos de FEACEM

- CEE participados por lo grupos de la Economía Social no incluidos en los anteriores.

- CEE identificados por las encuestas de CIRIEC y no adscritos por los puntos anteriores.

Así, conforme a estos criterios de clasificación y en atención a la forma jurídica, con los datos de CIRIEC-España, en 2017, serían sociedades limitadas el 59,4\% de los CEE de Economía Social (CEE ES) y el 95,7\% de los CEE de Economía Capitalista (CEE EC); mientras que las Asociaciones y Fundaciones representarían el 20,3\% de los CEE ES, 12,4\% las Sociedades Anónimas y 4,7\% las cooperativas.

60. Vid. MORATALLA SANTAMARÍA, P.: cit., pp. 20-25, y referencias ahí indicadas.

61. Recogiendo las palabras de la asociación Canaria de Centros Especiales de Empleo, vienen a señalar MENDOZA JIMÉNEZ, J., ROMÁN CERVANTES, C. \& HERNÁNDEZ LÓPEZ, M.: "La economía social...", cit., p. 227, que la limitación al ánimo de lucro como criterio de distinción entre CEE y CEE de iniciativa social, corre el riesgo de "crear discapacitados de primera y de segunda clase" bajo el argumento de que, dependiendo de la naturaleza de la empresa en la que trabajen, pueden tener más o menos oportunidades laborales. 
en sus Estatutos. Pero probablemente no evitará la creación, en particular, de asociaciones y fundaciones ficticias para cumplir las exigencias que se requieren para la consideración de CEE de iniciativa social y poder optar así en el porcentaje que se reserva a estos centros (además de las empresas de inserción) en las licitaciones de la contratación pública ${ }^{62}$.

\section{Conclusiones y cuestiones pendientes}

Las políticas de previsión, tratamiento, rehabilitación e integración de las personas con discapacidad y de atención especializada para garantizar su derecho al trabajo tienen una justificación constitucional y un reconocimiento en la Convención Internacional sobre los derechos de las personas con discapacidad de Nueva York de 13 de diciembre dc 2006, ratificada por España mediante Instrumento de ratificación publicado el 21 de abril de 2008, y a la que se encuentra vinculada la Unión Europea, mediante Decisión del Consejo, de 26 de noviembre de 2009. El artículo 26 de la Carta de los Derecho Fundamentales de La Unión Europea establece que La Unión reconoce y respeta el derecho de las personas discapacitadas a beneficiarse de medidas que garanticen su autonomía, su integración social y profesional y su participación en la vida de la comunidad. Al sector público, en sus distintos ámbitos de actuación le corresponde, pues, facilitar la integración en el mercado laboral de los trabajadores con discapacidad.

Los CEE están reconocidos en nuestro ordenamiento jurídico, desde hace casi 40 ańos, como un instrumento para evitar el apartamiento laboral que sufren las personas con discapacidad. Los CEE son una oportunidad de desarrollo profesional y, por ello, de autonomía. Como se ha venido diciendo, cuando se "inventan" este tipo de empresas, no se hace desde la óptica de desarrollar una actividad económica, que tiene como expectativa dominante la rentabilidad (aunque sea necesaria), sino desde el objetivo de crear empleo para personas que "el mercado laboral" no desea

62. MENDOZA JIMÉNEZ, J., ROMÁN CERVANTES, C. \& HERNÁNDEZ LÓPEZ, M.: "Los contratos reservados: una herramienta para el fortalecimiento de las entidades sociales", CIRIEC-España, Revista Jurídica de Economía Social y Cooperativa, no 33, 2018 pp. 311-312, apuntan que la introducción de la nueva figura CEE de iniciativa social para la que se limita la reserva, puede interpretarse como un intento de limitar el efecto que el ánimo de lucro podría tener sobre la labor social de este tipo de organizaciones. "La redacción de la disposición adicional cuarta de la LCSP puede, en efecto, ayudar a limitar lo que se define en este trabajo como "piratería social" [empresas que solo contratan empleados pertenecientes a esos colectivos para la ejecución del contrato]. Sin embargo, no cubre ni limita otros posibles casos de abusos como la creación de Centros Especiales de Empleo por parte de fundaciones y asociaciones que estén creadas y controladas por empresas con ánimo de lucro". 
contratar, por lo que "estamos en el corazón del concepto de economía social"63. La Ley española 5/2011, de Economía Social, no duda en incluirlos en el conjunto de las entidades de economía social.

Los CEE son un instrumento de lo que se conoce como empleo protegido. En la configuración actual de los CEE nuestro ordenamiento jurídico no establece ninguna limitación respecto de la naturaleza pública o privada de la entidad, ni de su forma jurídica, ni de su finalidad (lucrativa o no), ni de la titularidad, en su caso, de su capital social.

El objetivo principal de los CEE es realizar una actividad productiva de bienes o servicios y tienen como finalidad el asegurar un empleo remunerado para las personas con discapacidad, pero, a la vez, como hemos visto, son un medio de inclusión del mayor número de estas personas en el régimen de empleo ordinario. Conviene recuperar a los CEE como puente o tránsito hacia el empleo en empresa ordinaria. Así se recogía en el Acta del IV Encuentro Nacional de Investigadores y Profesionales sobre Economía Social, Autogestión y Empleo, celebrado en Valencia en junio de $2018^{64}$. A ello ayudaría, por ejemplo, facilitar, en especial, la transferencia de las personas con discapacidad intelectual -que, sin duda, constituyen el colectivo en el que es más complicada esa transferencia- entre los centros ocupacionales y los centros especiales de empleo ${ }^{65}$. Los datos muestran las mayores dificultades a que se enfrentan los trabajadores con discapacidad intelectual, por lo que cada vez se hace más necesario un tratamiento diferenciado de CEE en función del tipo de discapacidad de sus trabajadores ${ }^{66}$.

La normativa nacional y europea posibilita justificar la prioridad y reservas para los CEE (y empresas de inserción) en la contratación del sector público por su comportamiento diferente respecto de las empresas ordinarias ${ }^{67}$. Lo que no parece tan

63. Vid. CAVAS MARTÍNEZ, F. \& GRIMALDOS GARCÍA, M.: cit., pp. 172-173 y referencias ahí indicadas.

64. MONTALBÁN MOYA, R.: cit., p. 22.

65. Vid. CANTALAPIEDRA, J.: "ATADI. Centro especial de empleo", en La promoción del emprendimiento y la inserción social desde la economia social, Gemma Fajardo García (coord.). Centro Internacional de Investigación e Información sobre la Economía Pública, Social y Cooperativa, CIRIEC-Espańa, Valencia, 2018, p. 138, que pone en evidencia el problema que supone cuando la persona con discapacidad pasa más de 6 meses trabajando en el CEE que pierde su plaza en el Centro ocupacional, no pudiendo reservarla o suspenderla temporalmente.

66. Vid., GARCÍA SABATER, A.B.: cit., pp. 24-26.

67. Directiva 2014/24/UE del Parlamento Europeo y del Consejo, de 26 de febrero de 2014 sobre contratación pública y por la que se deroga la Directiva 2004/18/CE (DOUE de 28 de marzo de 2014)

Artículo 20 Contratos reservados. 
(pp. 55-91)

justificado es que esa prioridad y reservas se limite a determinados CEE, a los CEE de iniciativa social y, menos aun que, para ello, se utilice la Ley de contratos del sector público para modificar la Ley que configura los CEE, introduciendo una categoría ad hoc, que no dejará de generar conflictos.

La categoría de los CEE de iniciativa social añadida por la Ley de contratos del sector público de 2017 no deja de ser polémica y merece ser revisada. La Ley de Economía Social no distingue categorías de centros especiales de empleo y reclama la promoción de todos ellos, por lo que un tipo específico de CEE, que va a tener un trato ventajoso en la contratación pública, no encaja bien en la sistemática de la Ley de Economía Social.

El Dictamen del Comité Económico y Social Europeo: Hacia un marco jurídico europeo adaptado para las empresas de economía social, Ponente Alain Coheur, de 19 de junio de 2019 (DOUE de 28 de agosto de 2019), propone introducir en la legislación de la UE un marco jurídico adaptado a un mejor reconocimiento de las Entidades de Economía Social. "Este marco se basaría en un concepto nuevo, el de los «beneficios limitados», que definiría el conjunto de las empresas que pueden obtener beneficios pero cuyo fin no es distribuirlos entre sus propietarios, puesto que tienen

1. Los Estados miembros podrán reservar el derecho a participar en los procedimientos de contratación a talleres protegidos y operadores económicos cuyo objetivo principal sea la integración social y profesional de personas discapacitadas o desfavorecidas o prever la ejecución de los contratos en el contexto de programas de empleo protegido, a condición de que al menos el $30 \%$ de los empleados de los talleres, los operadores económicos o los programas sean trabajadores discapacitados o desfavorecidos.

2. La convocatoria de licitación deberá hacer referencia al presente artículo.

En lo que se refiere a nuestro derecho interno, conviene recordar lo previsto en la Ley 9/2017, de 8 de noviembre, de contratos del sector público:

Articulo 132. Principios de igualdad, transparencia y libre competencia.

1. Los órganos de contratación darán a los licitadores y candidatos un tratamiento igualitario y no discriminatorio y ajustarán su actuación a los principios de transparencia y proporcionalidad.

En ningún caso podrá limitarse la participación por la forma jurídica o el ánimo de lucro en la contratación, salvo en los contratos reservados para entidades recogidas en la disposición adicional cuarta.

2. La contratación no será concebida con la intención de eludir los requisitos de publicidad o los relativos al procedimiento de adjudicación que corresponda, ni de restringir artificialmente la competencia, bien favoreciendo o perjudicando indebidamente a determinados empresarios.

3. Los órganos de contratación velarán en todo el procedimiento de adjudicación por la salvaguarda de la libre competencia. Así, tanto ellos como la Junta Consultiva de Contratación Pública del Estado o, en su caso, los órganos consultivos o equivalentes en materia de contratación pública de las Comunidades Autónomas, y los órganos competentes para resolver el recurso especial a que se refiere el artículo 44 de esta Ley, notificarán a la Comisión Nacional de los Mercados y la Competencia o, en su caso, a las autoridades autonómicas de competencia, cualesquiera hechos de los que tengan conocimiento en el ejercicio de sus funciones que puedan constituir infracción a la legislación de defensa de la competencia. En particular, comunicarán cualquier indicio de acuerdo, decisión o recomendación colectiva, o práctica concertada o conscientemente paralela entre los licitadores, que tenga por objeto, produzca o pueda producir el efecto de impedir, restringir o falsear la competencia en el proceso de contratación. 
una finalidad de tipo solidario o de interés general" (Conclusiones y recomendaciones 1.5$)^{68}$.

En las observaciones particulares del Dictamen sobre Derecho de la competencia, se viene a decir que ese concepto de beneficios limitados debería aplicarse asimismo al Derecho de la competencia (3.2.2.1) y que, aun cuando para determinar el ámbito de aplicación de las normas de la competencia solo se utiliza como criterio el ejercicio de una actividad económica en un mercado, se podrian introducir ajustes en la fase de aplicación de las normas, a fin de tener en cuenta determinadas especificidades de las Entidades de Economía Social (3.2.2.2).

En fin, en lo que concierne a la contracción pública recoge que la Comunidad Europea considera que el acceso de las entidades de economía social a los contratos públicos es una cuestión que requiere atención y ha resaltado la dificultad de algunas para participar en las licitaciones (3.2.3.1) y que estas empresas quedan excluidas, a priori, de los contratos reservados. No obstante, existe una excepción general para los operadores económicos cuyo objeto principal sea la integración social y profesional de personas con discapacidad o desfavorecidas. Por otra parte, la Directiva 2014/24/UE brinda también a los Estados miembros la posibilidad de reservar contratos de servicios sanitarios, sociales y culturales a empresas con beneficios limitados que cumplan determinados criterios de funcionamiento. (3.2.3.2) ${ }^{69}$.

Este nuevo concepto que se propone de entidades de "beneficios limitados" quizá pueda ser una vía para un mejor reconocimiento de las entidades de economía social y una mejor atención, y más respetuosa con el derecho de la competencia, en las reservas de contratos del sector público. Este nuevo concepto, incorporado por las Administraciones públicas en los pliegos de contratación, facilitaría sin distorsiones -entendemos nosotros- la participación de las entidades de economía social en las licitaciones.

68. Pide también a la Comunidad Europea "que elabore un estudio sobre el concepto de «beneficios limitados» y sobre los modelos de empresas que se ajustan a este funcionamiento. Este estudio permitiría determinar mejor la necesidad de marcos jurídicos, financieros y fiscales adecuados para la preservación de las capacidades competitivas de las empresas interesadas y, en su caso, daría lugar a la elaboración de buenas prácticas".

69. Se añade, también, que Hay que señalar, con todo, que el sistema de licitación, es decir, la puesta en competencia entre empresas inspirada en el modelo liberal y privado, no siempre sitúa a las empresas con beneficios limitados en una posición competitiva cómoda. También aquí, su tamaño en ocasiones modesto o el acceso más difícil a las fuentes de financiación de la inversión pueden representar una desventaja competitiva, cualquiera que sea el tipo de actividad realizada. Por lo tanto, la división de los contratos en lotes y los criterios de adjudicación a la oferta económicamente más ventajosa deberían tener en cuenta esta diferencia de situación (3.2.3.3). 


\section{Bibliografía}

AA.VV.: Libro Blanco del cooperativismo y la economia social valenciana (Dirs. CHAVES ÁVILA, R., JULIÁ IGUAL, J.F. \& MONZÓN CAMPOS, J.L.), CIRIEC-España, Valencia, 2019.

ANDRÉS PÉREZ, Ma del R.: Los contratos reservados en la ley 9/2017, del 8 de noviembre, Observatorio Contratación Pública, http://www.obcp.es/index.php/ mod.opiniones/mem.detalle/id.337/relcategoria.208/relmenu.3/chk.0a06bb42570ad5fa570d9459e03828fc, 2018.

ANGULO GARZARO, A.: "La transposición del artículo 20 de la Directiva 2014/24/UE a la Ley de contratos del sector público (LCSP) y su incidencia en la competencia. Especial referencia a los centros especiales de empleo de iniciativa social”, Revista Aranzadi Unión Europea, no. 3, 2019, pp. 1-8.

BURZACO SAMPER, M.: "Concurrencia competitiva, igualdad entre licitadores y discriminación positiva en las reservas de contratos: un análisis desde los conflictos”, CIRIEC-España, Revista Jurídica de Economía Social y Cooperativa, no 35, 2019, pp. 1-44.

CABANA TENA, A.: El concepto de grupo de sociedades, Tirant lo Blanch. Valencia, 2019.

CALVO VÉRGEZ, J.: "La proyección de la nueva Ley 9/2017, de 8 de noviembre, de Contratos del sector público, sobre el ámbito de la Economía social: un nuevo marco regulatorio para las entidades del tercer sector", Revista Aranzadi Doctrinal, $\mathrm{n}^{\circ}$. 4, 2019, pp. 1-19.

CANTALAPIEDRA, J.: “ATADI. Centro especial de empleo”. En La promoción del emprendimiento y la inserción social desde la economía social (Coord. FAJARDO GARCÍA, G.), CIRIEC-España, Centro Internacional de Investigación e Información sobre la Economía Pública, Social y Cooperativa, Valencia, 2018, pp. 135-139.

CAVAS MARTÍNEZ, F. \& GRIMALDOS GARCÍA, M.: "Los centros especiales de empleo". En La empresa social y su organización jurídica (Coord. ANDREU MARTÍ, Ma.M.), Marcial Pons, 2014, pp. 169-201. 
COMITÉ ECONÓMICO Y SOCIAL EUROPEO: Dictamen: Hacia un marco jurídico europeo adaptado para las empresas de economía social. Pleno de 19 de junio de 2019. Ponente COHEUR, A. https://eur-lex.europa.eu/legal-content/ ES/TXT/?uri=uriserv:OJ.C_.2019.282.01.0001.01.SPA\&toc=OJ:C:2019:282:FULL, 2019.

CUETO IGLESIAS, B. et al.: Trayectorias laborales de las personas con discapacidad y centros especiales de empleo, análisis empirico con la MCVL. http://www.seg-social. es/wps/wcm/connect/wss/be250769-afa4-4d91-ba1d-e4277cda9804/F10_07N. pdf?MOD=AJPERES\&amp;CVID=, 2008.

FAJARDO GARCÍA, G. "La identificación de las empresas de economía social en España. Problemática jurídica”, REVESCO, Revista de Estudios Cooperativos, no 128, pp. 2018, 99-126.

GARCÍA DIEGO, D.A.: Declaraciones en "FEACEM valora positivamente la sentencia de la Audiencia Nacional sobre Centros Especiales de Empleo", Siglo XXI, 18 de noviembre de 2019.

GARCÍA SABATER, A.B.: "Centros especiales de empleo de iniciativa social. Avances legislativos y ajustes necesarios", CIRIEC-España, Revista Jurídica de Economía Social y Cooperativa, no 35, 2019, pp. 1-29.

JORDÁN DE URRÍES VEGA, F. DE B. \& VERDUGO ALONSO, M.A.: Informe sobre la situación de los Centros Sociales de empleo en España, Universidad de Salamanca, http://sid.usal.es/idocs/F8/FDO25153/InformeMTIN_Centros_EspecialesdeEmpleo.pdf, 2010

LÓPEZ PENABAD, M.C., MASIDE SANFIZ, J.M. \& TORRELLLES MANENT, J.: "Análisis económico y social de los centros especiales de empleo: un estudio en Galicia”, REVESCO, Revista de Estudios Cooperativos, no 132, 2019, pp. 169-194. MARTÍN LORENZO, B.: "Reserva de contratos a los centros especiales de empleo de iniciativa social: régimen jurídico y doctrina consultiva y de los Tribunales Administrativos de recursos contractuales", CIRIEC-España, Revista Jurídica de Economia Social y Cooperativa, no 35, 2019, pp. 1-31.

MENDOZA JIMÉNEZ, J., ROMÁN CERVANTES, C. \& HERNÁNDEZ LÓPEZ, M.: "Los contratos reservados: una herramienta para el fortalecimiento de las entidades sociales", CIRIEC-España, Revista Jurídica de Economía Social y Cooperativa, no 33, 2018, 2018, pp. 295-332.

MENDOZA JIMÉNEZ, J., ROMÁN CERVANTES, C. \& HERNÁNDEZ LÓPEZ, M.: "La economía social y la contratación pública: la herramienta de los contratos reservados", CIRIEC-España, Revista de Economía Pública Social y Cooperativa, $n^{\circ} .97,2019$, pp. 213-244. 
MONTALBÁN MOYA, R.: "Acta del IV Encuentro Nacional de investigadores y profesionales sobre economía social, autogestión y empleo (Valencia 14-25 de junio 2018)". En La promoción del emprendimiento y la inserción social desde la economía social (Coord. FAJARDO GARCÍA, G.), CIRIEC-España, Centro Internacional de Investigación e Información sobre la Economía Pública, Social y Cooperativa, Valencia, 2018, pp. 9-23.

MONZÓN CAMPOS, J.L \& HERRERO MONTAGUD, M.: "Identificación y análisis de las características identitarias de la empresa social europea: aplicación a la realidad de los Centros Especiales de Empleo de la economía española”, CIRIEC-España, Revista de Economía Pública, Social y Cooperativa, no 87, 2016, pp. 295-326.

MORATALLA SANTAMARÍA, P.: "Centros especiales de empleo", CIRIEC-España, Revista Jurídica de Economía Social y Cooperativa, no. 29, 2016, pp. 235-274

MUÑOZ GARCÍA, C.: "La Ley General de derechos de las personas con discapacidad y de su inclusión socio-laboral", La Ley, nº. 8231, 2 de enero, 2014.

ODISMET: Informe 4 del observatorio sobre discapacidad y mercado de trabajo de la fundación ONCE, https://www.odismet.es/informes-publicaciones, 2014.

PANIAGUA ZURERA, M.: Las empresas de la economía social más allá del comentario a la Ley 5/2011, de economía social, Marcial Pons. Madrid, 2011.

RONCERO SÁNCHEZ, A.: "Importancia económica, régimen legal y características propias de las cooperativas agrarias y de las sociedades agrarias de transformación”. En Cooperativas agrarias y sociedades agrarias de transformación (Dir. PULGAR EZQUERRA, J., Coord. VARGAS VASSEROT, C.), Dykison, Madrid, 2006, pp. 21-43

SÁNCHEZ PACHÓN, L.A.: "La delimitación de las entidades y organizaciones de economía social en la próxima ley reguladora del sector”, CIRIEC-España, Revista de Economia Pública, Social y Cooperativa, no. 66, 2009, págs. 61-84.

SÁNCHEZ PACHÓN, L.A.: "El reconocimiento de la economía social y de sus agentes en el Proyecto de Ley de Economía Social”, Noticias de la Economía Pública Social y Cooperativa, no. 54, 2010, págs. 53-58.

SÁNCHEZ PACHÓN, L.A \& PÉREZ CHINARRO, E.: "Las entidades de economía social como protagonistas de un nuevo modelo de emprendimiento y medidas legales de apoyo al emprendimiento", CIRIEC-España, Revista de Economía Pública, Social y Cooperativa, no. 84, 2015, págs. 35-62. 